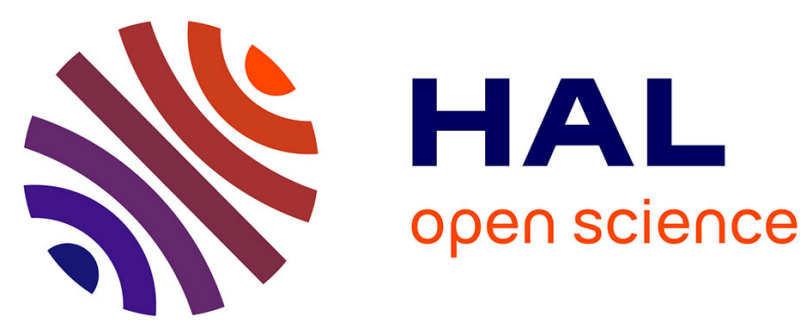

\title{
Effect of mass and habitat on the shape of limb long bones: A morpho-functional investigation on Bovidae (Mammalia: Cetartiodactyla)
}

Cyril Etienne, Andréa Filippo, Raphael Cornette, Alexandra Houssaye

\section{To cite this version:}

Cyril Etienne, Andréa Filippo, Raphael Cornette, Alexandra Houssaye. Effect of mass and habitat on the shape of limb long bones: A morpho-functional investigation on Bovidae (Mammalia: Cetartiodactyla). Journal of Anatomy, 2021, 238 (4), pp.886-904. 10.1111/joa.13359 . hal-03159183

\section{HAL Id: hal-03159183 \\ https://hal.science/hal-03159183}

Submitted on 4 Mar 2021

HAL is a multi-disciplinary open access archive for the deposit and dissemination of scientific research documents, whether they are published or not. The documents may come from teaching and research institutions in France or abroad, or from public or private research centers.
L'archive ouverte pluridisciplinaire HAL, est destinée au dépôt et à la diffusion de documents scientifiques de niveau recherche, publiés ou non, émanant des établissements d'enseignement et de recherche français ou étrangers, des laboratoires publics ou privés. 
4 Cyril Etienne ${ }^{1, *}$, Andréa Filippo $^{1}$, Raphaël Cornette ${ }^{2}$, Alexandra Houssaye $^{1}$.

$5 \quad{ }^{1}$ UMR 7179, Mécanismes Adaptatifs et Evolution, Muséum National d'Histoire Naturelle, 6 Centre National de la Recherche Scientifique, CP 55, 57 rue Cuvier, 75005 Paris, France.

$7 \quad{ }^{2}$ Institut de Systématique, Evolution, Biodiversité (ISYEB), Muséum national d'Histoire 8 naturelle, Sorbonne Université, CNRS, Ecole Pratique des Hautes Etudes, Université des 9 Antilles ; CP 50, 57 rue Cuvier, 75005 Paris, France.

$10 *$ corresponding author, cyril.etienne@cri-paris.org

11 Running title: Functional morphology of bovid limb long bones 


\section{Abstract}

Limb long bones are essential to an animal's locomotion, and are thus expected to be heavily influenced by factors such as mass or habitat. Because they are often the only organs preserved in the fossil record, understanding their adaptive trends is key to reconstructing the palaeobiology of fossil taxa. In this regard, the Bovidae has always been a prized group of study. This family is extremely diverse in terms of both mass and habitat, and it is expected that their bones will possess adaptations to both factors. Here we present the first $3 \mathrm{D}$ geometric morphometric study focusing on bovid limb long bones. We used anatomical landmarks as well as curve and surface sliding semi-landmarks to accurately describe the stylopod and zeugopod bones. We included 50 species from ten of the twelve currently recognized tribes of bovids, ranging from 4.6 to $725 \mathrm{~kg}$, and living in open plains, forests, mountains or anywhere inbetween. Shape data were correlated with the mean mass of the species and its habitat, even when taking into account the phylogenetic history of our sample. Bones pertaining to heavy species are more robust, adapted for a better repartition of stronger forces. Articulations are especially affected, being proportionally much larger in heavier species. Muscle insertion areas are unevenly affected. Insertion areas of muscles implied in body support and propulsion show a strong increase in their robustness when compared to insertion areas of muscles acting on the limb mostly when it is off the ground. Habitat influences the shape of the humerus, the radiusulna, and the femur, but not of the tibia, whether the phylogeny is taken into account or not. Specific habitats tend to be associated with particular features on the bones. Articulations are proportionally wider in open-habitat species, and the insertion areas of muscles involved in limb extension and propulsion are wider, reflecting the fact that open habitat species are more cursorial and rely on fast running to avoid predators. Forest and mountain species generally present similar adaptations for increased manoeuvrability, such as a round femoral head, and generally have more gracile bones.

Key words: limb long bones - functional morphology - body mass - habitat - phylogeny geometric morphometrics - Bovidae 


\section{Introduction}

In most terrestrial vertebrates, limb long bones are essential to locomotion. They provide support for the weight of the animal, and a rigid attachment point for the muscles also responsible for body support and movement (Hildebrand, 1982; Hildebrand et al., 1985). Several factors are expected to exert a strong selective pressure on the shape of these bones. Mass is among the strongest of those factors, if not the strongest one (Biewener, 1989; Hildebrand, 1982; Polly, 2008). This is because the ability of bones to resist forces depends on their cross-sectional area, whether the forces are expected to be proportional to the animal's weight, a volume (Biewener, 1989). This means that the stresses, i.e. the forces per unit area the bones are subject to, should increase proportionally to the animal's weight. In order to avoid this, heavier animals typically run with a more upright posture of their limbs. This increases the mechanical advantage of the lever systems of the limbs, allowing larger animals to move by using weaker than expected muscles, exerting lower stresses on the bones (Biewener, 1989, Biewener \& Patek, 2018). Past a certain mass however (Biewener, 1989, 2005 proposes around $300 \mathrm{~kg}$ ), a threshold is reached where it becomes difficult for the limb to straighten up any further. Therefore, in order for the stresses in the bones to remain constant, locomotor performances will decline, and bone shape will undergo more extreme changes (Biewener, 1989; Bertram and Biewener, 1990; Christiansen, 1999a). When mass increases, the most obvious change in bone shape generally observed is an increase in robustness, i.e. diameter relative to length (Schmidt-Nielsen, 1984). Additionally, muscle insertion areas will become larger, presumably accommodating for stronger muscles (see e.g. Doube et al., 2009; Walmsley et al., 2012; Mallet et al., 2019; Martin et al., 2019). This is of course also influenced by phylogenetical factors (Biewener \& Patek, 2018). Adaptations to a heavy weight can differ markedly between taxa with a similar weight; e.g. hippos which possess very stout limbs and cannot gallop or trot, and rhinos which have more elongate limbs and are able of galloping (Wilson and Mittermeier, 2011).

Another factor strongly influencing bone shape is the habitat in which a species lives (Kappelman, 1988; Polly, 2008; Curran, 2012; Dunn, 2018). Terrestrial mammals obviously present a very different skeleton from that of aquatic ones (Hildebrand, 1982; Hall, 2008). More subtly, species living in open, plains habitats present specific adaptations that differ from those of species living in closed, forested habitats (see e.g. Kappelman, 1988; Plummer et al., 2008; Curran, 2012, 2018; Barr, 2014). This is notably due to differences in the substrate in which the animals move (e.g. the flat, two-dimensional ground of a savannah versus the complex, almost 
three-dimensional system of bushes and roots in a forest; Kappelman, 1988). Another reason will be differences in predator-avoidance strategies. Open-habitat species must be fast and agile runners capable of outrunning or exhausting potential predators on a mostly even ground, whereas closed-habitat species presumably rely more on camouflage, and have to navigate on a very complex substrate if they do have to flee (Kappelman, 1988; Kappelman et al., 1997; Plummer et al., 2008). Identifying precisely the adaptations of the shape of the long bones associated with a particular mass and habitat could therefore be extremely helpful in order to reconstruct the paleobiology and paleoenvironment of extinct animals.

To study the morphological features of the limb long bones linked to habitat and mass, Bovidae have always been a prized group. They are the most diverse family of large mammals on earth today, comprising 279 species spread out in twelve different tribes (Castelló, 2016). Bovids vary greatly in terms of mass, the smallest species (the royal antelope, Neotragus pygmaeus) weighing only two kilograms whereas the heaviest one (the Asian wild water buffalo, Bubalus arnee) can weigh up to $1200 \mathrm{~kg}$ (Castelló, 2016). They also vary in terms of habitat, and can be found in open savannahs, dense rainforests, steep mountains, or snowy environments. For all these reasons, bovid limb bones have been extensively studied, in various domains such as functional morphology, zooarcheaology and palaeoecology. For instance, numerous studies have tried to use bovid bones to predict paleoenvironments. DeGusta and Vrba (2003) and Plummer et al. $(2008,2015)$ have used linear measurements on the astragalus to predict a bovid's habitat, and Barr (2014) showed that this relationship holds even when controlling for phylogenetic signal and size effect. Kappelman $(1991,1988)$ and Kappelman et al. (1997) have studied the bovid femur using linear measurements, areas and ratios. They determined, for instance, that bovids living in an open, plains habitat presented a cylindrical femoral head that help stabilize the hip joint, whereas bovids living in closed, forested habitats presented a spherically-shaped femoral head better suited for axial rotation of the femur, adduction and abduction, and overall, manoeuvrability. They were able to use this to reconstruct the habitat of early hominids. Several studies have examined the allometry in the limb bones. Scott (1985) has studied an extensive sample of bovids and concluded that bones become much thicker in heavier species, with also a relative shortening of the limb. Mendoza and Palmqvist (2006) showed that body mass is highly correlated with the width of the proximal articular surface of the radius, as well as the other articular surfaces in general, particularly those of the elbow and the knee. 
106 Our study focuses on characterising the shape of each of the limb long bones of bovids 107 (stylopodium and zeugopodium), and associating different habitats and extremes of masses 108 with a particular shape. This is conducted using a 3D geometric morphometric study (Zelditch 109 et al., 2012; Adams et al., 2013), the first to our knowledge performed on bovid limb long 110 bones. Based on previous studies, we expect both mass and habitat to have a strong impact on 111 the shape of long bones. We expect bones of more massive species to be more robust in shape, 112 with relatively larger articular facets and muscle insertion areas, and a relatively wider 113 diaphysis. We expect bones of species living in open habitats to present adaptations for a high 114 degree of cursoriality, and bones of species living in closed or mountain habitats to present 115 adaptations for better manoeuvrability. We expect that the 3D shape comparison approach 116 permitted by geometric morphometrics will enable a better characterization and quantification 117 of shape variations linked to mass and habitat across bovids, as well as confirm and expand 118 previous results found in bovids with other techniques. This would increase our understanding 119 of the link between form and function in bone morphology, and especially of the impact of mass 120 and habitat on skeletal architecture. 


\section{Material}

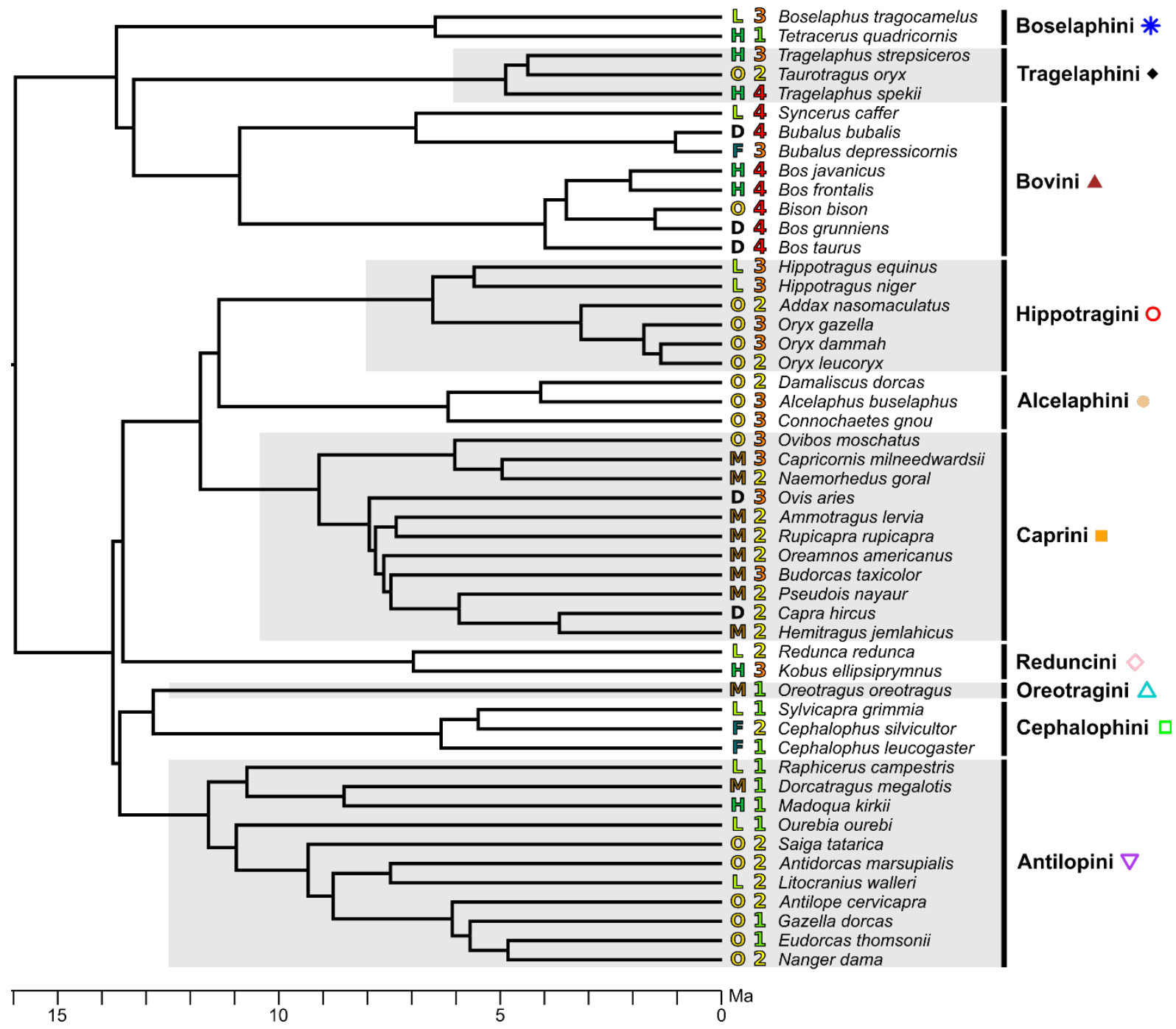

124 Figure 1. Phylogenetic tree used in this study, modified from Bibi (2013), with indications of habitat 125 and mass for each species. $\mathbf{O}$ : open habitat; $\mathbf{L}$ : light cover habitat; $\mathbf{H}$ : heavy cover habitat; $\mathbf{F}$ : forest 126 habitat; M: mountain habitat; $\mathbf{D}$ : domesticated species. 1: mean mass under or equal to $20 \mathrm{~kg} ; \mathbf{2}$ : mean 127 mass from 21 to $100 \mathrm{~kg}$; 3: mean mass from 101 to $300 \mathrm{~kg} ; 4$ : mean mass above $300 \mathrm{~kg}$.

128 Table 1. Number of bones studied per tribe.

\begin{tabular}{lrrrrr}
\multicolumn{1}{c}{ Tribe } & Humerus & \multicolumn{1}{c}{ Femur } & Tibia & Radius-ulna & Total \\
Alcelaphini & 6 & 6 & 6 & 4 & 22 \\
Antilopini & 13 & 16 & 13 & 7 & 49 \\
Boselaphini & 4 & 4 & 4 & 3 & 15 \\
Bovini & 15 & 14 & 14 & 13 & 56 \\
Caprini & 18 & 20 & 15 & 15 & 68 \\
Cephalophini & 1 & 3 & 2 & 1 & 7 \\
Hippotragini & 9 & 10 & 10 & 9 & 38 \\
Oreotragini & 2 & 2 & 2 & 0 & 6
\end{tabular}




\begin{tabular}{lrrrrr} 
Reduncini & 4 & 4 & 2 & 3 & 13 \\
Tragelaphini & 3 & 4 & 4 & 3 & 14 \\
\hline Total & $\mathbf{7 5}$ & $\mathbf{8 3}$ & $\mathbf{7 2}$ & $\mathbf{5 8}$ & 288 \\
\hline
\end{tabular}

We studied a total of 288 stylopod and zeugopod bones from 50 species among ten of the twelve currently recognized tribes of bovids (see Fig. 1, Table 1, and Table S1 for the list of all specimens). Specimens were chosen pending on availability and with the aim of obtaining a representative sample of the bovid family in terms of mass, habitat and phylogeny. Neotragini and Aepycerotini are the only tribes for which we did not find any member in the collections we visited. Specimens come from the collections of the Muséum National d'Histoire Naturelle (MNHN, Paris, France), and the Museum für Naturkunde (ZMB, Berlin, Germany).The taxonomy of the family follows Castelló (2016). All bones belong to adult or subadult specimens, as indicated by the complete fusing of their epiphyses to their diaphyses. We tried to get two specimens by species when possible, depending on material available. Per bone, our sample includes 43 species for the humerus (32 for which we have two specimens), 38 species for the radius-ulna ( 20 with two specimens), 48 species for the femur ( 35 with two specimens) and 45 species for the tibia ( 27 with two specimens). The anatomical nomenclature follows De Iuliis \& Pulerà (2011) as well as anglicised terms from (Barone, 1999, 2010).

\section{Mass and habitat attribution}

Mass estimates were retrieved from Castelló (2016). Usually, two ranges of mass are available, one for each sex. The sex of the specimens sampled was usually unknown; considering the need of a unique value for the analyses, we used the mean of the lowest and highest values provided for the whole species. The average species masses range from $4.6 \mathrm{~kg}$ for the lightest species (Kirk's dik-dik, Madoqua kirkii) to $725 \mathrm{~kg}$ for the heaviest one (the domestic cow, Bos taurus, Table 2). For the scimitar oryx (Oryx dammah), the mass range is taken from Mungall (2007) since the value given by Castelló (2016) is for males only. For the hartebeest (Alcelaphus buselaphus), Castelló (2016) considers that it should be split into seven independent species and reports separate mass values for each of them. Given that we were unable to reassign the specimens we studied to one of those species, the range of mass used is that of all the species that were once regrouped under $A$. buselaphus.

Habitat attribution follows the categories initially proposed by Kappelman et al. (1997), adding a mountain category as proposed by Scott \& Barr (2014). We used an additional separate category for the domesticated species since they have undergone artificial selective pressures 
159 that could alter their bone shape and are kept in enclosures that do not necessarily reflect their

160 original habitat. We used the species assignments to habitat categories of DeGusta \& Vrba

161 (2003), Plummer et al. (2008) and Scott \& Barr (2014). When a species of our sample had not

162 been assigned to a habitat category by any of them, or when two publications disagreed on the

163 category one species should be classified into, we assigned the species to a habitat category

164 ourselves based on Castelló (2016). Five species are classified as domesticated species, three

165 as forest-dwellers, seven as heavy cover species, nine as light cover species, ten as mountain

166 species and 16 as open-habitat species (Table 2).

167

168

169

Table 2. Mass and habitat assigned to each of our species, based on DeGusta \& Vrba (2003), Plummer et al. (2008), Scott \& Barr (2014), and Castelló (2016) for habitat, and Castelló (2016) for masses.

\begin{tabular}{|c|c|c|c|}
\hline Tribe & Species & Habitat & Mass (kg) \\
\hline Alcelaphini & Alcelaphus buselaphus & Open & $169(120-218)$ \\
\hline Alcelaphini & Connochaetes gnou & Open & $145(110-180)$ \\
\hline Alcelaphini & Damaliscus pygargus & Open & $71(56-86)$ \\
\hline Antilopini & Antidorcas marsupialis & Open & $29(20-38)$ \\
\hline Antilopini & Antilope cervicapra & Open & $37.5(19-56)$ \\
\hline Antilopini & Dorcatragus megalotis & Mountain & $11(9-13)$ \\
\hline Antilopini & Eudorcas thomsonii & Open & $19(13-25)$ \\
\hline Antilopini & Gazella dorcas & Open & $19(15-23)$ \\
\hline Antilopini & Litocranius walleri & Light cover & $40(30-50)$ \\
\hline Antilopini & Madoqua kirkii & Heavy cover & $4.6(2.7-6.5)$ \\
\hline Antilopini & Nanger dama & Open & $57.5(40-75)$ \\
\hline Antilopini & Ourebia ourebi & Light cover & $12.5(8-17)$ \\
\hline Antilopini & Raphicerus campestris & Light cover & $11.5(7-16)$ \\
\hline Antilopini & Saiga tatarica & Open & $36(21-51)$ \\
\hline Boselaphini & Boselaphus tragocamelus & Light cover & $205(200-290)$ \\
\hline Boselaphini & Tetracerus quadricornis & Heavy cover & $20(15-25)$ \\
\hline Bovini & Bison bison & Open & $679(360-998)$ \\
\hline Bovini & Bos frontalis & Heavy cover & $455(350-560)$ \\
\hline Bovini & Bos grunniens & Domesticated & 395 (197-593) \\
\hline Bovini & Bos javanicus & Heavy cover & $600(400-800)$ \\
\hline Bovini & Bos taurus & Domesticated & $725(150-1300)$ \\
\hline Bovini & Bubalus bubalis & Domesticated & $700(400-1000)$ \\
\hline Bovini & Bubalus depressicornis & Forest & $225(200-250)$ \\
\hline Bovini & Syncerus caffer & Light cover & $625(350-900)$ \\
\hline Caprini & Ammotragus lervia & Mountain & $87.5(30-145)$ \\
\hline Caprini & Budorcas taxicolor & Mountain & $250(150-350)$ \\
\hline Caprini & Capra hircus & Domesticated & $66.5(20-113)$ \\
\hline Caprini & Capricornis milneedwardsii & Mountain & $112.5(85-140)$ \\
\hline Caprini & Hemitragus jemlahicus & Mountain & $85(30-140)$ \\
\hline Caprini & Nemorhaedus goral & Mountain & $38.5(35-42)$ \\
\hline Caprini & Oreamnos americanus & Mountain & $95(60-130)$ \\
\hline Caprini & Ovibos moschatus & Open & $295(180-410)$ \\
\hline Caprini & Ovis aries & Domesticated & $102.5(45-160)$ \\
\hline
\end{tabular}




\begin{tabular}{l|lll} 
Caprini & Pseudois nayaur & Mountain & $53.5(32-75)$ \\
Caprini & Rupicapra rupicapra & Mountain & $38(14-62)$ \\
Cephalophini & Cephalophus leucogaster & Forest & $17.5(14-21)$ \\
Cephalophini & Cephalophus silvicultor & Forest & $62.5(45-80)$ \\
Cephalophini & Sylvicapra grimmia & Light cover & $18(10-26)$ \\
Hippotragini & Addax nasomaculatus & Open & $92.5(60-125)$ \\
Hippotragini & Hippotragus equinus & Light cover & $257.5(215-300)$ \\
Hippotragini & Hippotragus niger & Light cover & $205(160-250)$ \\
Hippotragini & Oryx dammah & Open & $150.5(91-210)$ \\
Hippotragini & Oryx gazella & Open & $227.5(180-275)$ \\
Hippotragini & Oryx leucoryx & Open & $64.5(54-75)$ \\
Oreotragini & Oreotragus oreotragus & Mountain & $13.5(9-18)$ \\
Reduncini & Kobus ellipsiprymnus & Heavy cover & $217.5(160-275)$ \\
Reduncini & Redunca redunca & Light cover & $50(35-65)$ \\
Tragelaphini & Taurotragus oryx & Open & $575(450-700)$ \\
Tragelaphini & Tragelaphus spekii & Heavy cover & $87.5(50-125)$ \\
Tragelaphini & Tragelaphus strepsiceros & Heavy cover & $217.5(120-315)$
\end{tabular}

\section{Data acquisition}

Most of the specimens were digitized using an Artec Eva surface scanner and the Artec

173 Studio Professional v12.1.5.1 software (Artec 3D, 2018). The smallest specimens were

174 digitized using a Nikon D5500 camera (automatic mode, without flash, focal length $50 \mathrm{~mm}$,

175 aperture f/1.8) and the photogrammetry software Agisoft PhotoScan v1.4.0 (Agisoft LLC,

176 2017). The 3D meshes were then exported, decimated down to 200,000 faces and mirrored to

177 have only right side bones, using MeshLab v2016.12 (Cignoni et al., 2008).

\section{Geometric morphometrics}

179 Table 3. Number of anatomical landmarks, curve semi-landmarks and surface semi-landmarks placed 180 on each bone.

\begin{tabular}{r|c|c|c|c|} 
Bone & $\begin{array}{c}\text { Anatomical } \\
\text { landmarks }\end{array}$ & $\begin{array}{c}\text { Curve semi- } \\
\text { landmarks }\end{array}$ & $\begin{array}{c}\text { Surface semi- } \\
\text { landmarks }\end{array}$ & Total \\
\hline Humerus & 23 & 160 & 576 & 759 \\
\hline Radius-ulna & 17 & 208 & 365 & 590 \\
\hline Femur & 21 & 186 & 565 & 772 \\
\hline Tibia & 19 & 178 & 500 & 697 \\
\hline
\end{tabular}

To analyse shape variations in our sample, we performed 3D geometric morphometrics in

183 order to quantify the shape of each bone. Bone shape was modelled using three kinds of

184 landmarks: anatomical landmarks, semi-landmarks sliding on curves, and semi-landmarks 185 sliding on surfaces (Gunz et al., 2005; Gunz and Mitteroecker, 2013). Landmarks were defined 
and placed by a single operator (Table 3, Tables S2-S5, Figs. S1-S4). Landmarks and curves were placed on the meshes using the IDAV Landmark software package (Wiley, 2005). All the analyses and statistical tests were run using R (R Development Core Team, 2005) and RStudio (RStudio, Inc., 2018). The curves were resampled using the algorithm provided in Botton-Divet et al. (2016), in order to reduce the number of curve semi-landmarks. The algorithm uses the coordinates of the semi-landmarks of each curve to return a given number of equidistant points per curve. The new curve semi-landmarks were then projected on the meshes using the closemeshKD function of the Morpho R package (Schlager et al., 2018), to ensure that each curve semi-landmark was indeed placed on the surface of the mesh. The function uses the coordinates of each semi-landmark to calculate its closest match on the surface of the mesh.

As for the surface semi-landmarks, a template was designed for each bone type. A specimen was arbitrarily chosen among those assessed by eye to be the closest to the average and used to design the template (Bos taurus MNHN 1926-302 for the humerus, Connochaetes gnou MNHN 2013-26 for the radius-ulna, and Damaliscus pygargus ZMB 70722 for both the femur and tibia). Surface semi-landmarks were manually added to this template, in order to cover the whole surface. We used this template to project automatically the surface semi-landmarks on the surface of all the other specimens using the placePatch function of the Morpho R package (see Schlager et al., 2018). This was followed by a relaxation step using the relaxLM function, to ensure that projected points were spread across the entire surface of the meshes. Curve and surface sliding semi-landmarks were then slid to minimize the bending energy of a thin plate spline (TPS, see Mitteroecker \& Gunz, 2009; Gunz \& Mitteroecker, 2013) between each specimen and the template at first, and then two times between the result of the preceding step and the Procrustes consensus of the complete dataset, using the slider $3 \mathrm{~d}$ function. All the specimens were checked at each step using the checkLM function, to ensure that the semilandmarks were placed correctly.

All the landmarks were superimposed using a Generalized Procrustes Analysis (GPA(Rohlf and Slice, 1990), which translates, scales and rotates each set of landmarks in order to remove the information of size, position and angle and minimize the sum of the square distances between landmark configurations. The aligned landmarks coordinates were then used in a Principal Component Analysis (PCA) in order to reduce dimensionality of the dataset and visualize the distribution of the individuals in the morphometric space. Thin Plate Splines (TPS, see (Klingenberg, 2013) were used to visualize the results of our analyses: for each set of landmarks on the four bones, the mean-shape generated by the GPA was mapped onto the specimen closest to the mean value. Then, this mean-shaped model was deformed using TPS 
towards the shape resulting from our analyses (e.g. the shape corresponding to the maximal 221 theoretical mass). This allowed us to obtain the complete 3D models of theoretical bones corresponding for instance to the average heavy bovid or to the average bovid living in an open habitat, according to our sample. When shape differences were subtle and not clearly visible to the naked eye, colour maps were applied on the theoretical bones showing the local shape deviation from a reference model, using the meshDist function of the Morpho $\mathrm{R}$ package. The function calculates the distance between a reference mesh and another mesh along every vertex of the reference mesh.

In order to test the repeatability of our set of landmarks, we placed each of the anatomical landmarks five times on our two specimens of Oryx leucoryx and our two specimens of Oryx dammah. We could not use specimens belonging to only one species, as we do not have any species with more than two specimens. The four specimens were assessed by sight to be the four morphologically closest ones, and belong to phylogenetically very close species (Fig. 1).

233 For each bone, these 20 landmarks sets were then superimposed using a GPA and visualized 234 using a PCA, to check that landmark error per specimen was smaller than inter individual variation (Fig. S5).

\section{Statistical analyses}

All our tests, except the K-mult (see below), were performed on the Procrustes coordinates of the specimens. When two specimens were available for a species, the average of the Procrustes landmark coordinates of the two specimens was used. Three tests were performed for each of the four limb long bones:

1. A test of phylogenetic signal in the data, using a multivariate $K$ statistic (K-mult), based on all the PC-scores. It compares the observed rate of morphological change to the expected change under a Brownian motion (see Adams, 2014a; Blomberg et al., 2003). The phylogeny used is the one in Figure 1. This was performed using the K.mult function of the phylocurve R package (Goolsby, 2015).

2. A multivariate analysis of covariance (MANCOVA), against both mass and habitat, with the procD.lm function of the geomorph R package (Adams et al., 2018). The logarithm of the cubic root of the mass was used. This tested the influence of the species' mean mass and habitat on the shape of the bones in our sample. Shape data corresponding to the minimum and maximum mass and to each habitat were also extracted, if the test was significant. 
3. A Phylogenetic Generalised Least Squares (PGLS) regression, again to test the influence 252 of mass and habitat but this time in a phylogenetic framework (Adams, 2014b). This assumes 253 a Brownian model of evolution. This was performed with the procD.pgls function of the 254 geomorph R package.

255 To test the independence of mass and habitat in our sample, Student's t-tests were performed 256 to assess if each habitat category had a different mean mass from the others. This was done 257 separately for each bone, as our sample differed slightly between each bone. Considering we have six categories of habitat, this resulted in 15 pair-wise comparisons per bone, which may make it necessary to perform statistical corrections of the p-values in order to lower the risk of one or several false positives. There is, however, no consensus in the literature on whether or not this should be done, as although it lowers the risk of false positives, it increases the risk of false negatives (Cabin and Mitchell, 2000; Streiner and Norman, 2011). We therefore report both the corrected and uncorrected p-values. We used the p.adjust function of the stats $\mathrm{R}$ package, using a Benjamini-Hochberg correction (Benjamini and Hochberg, 1995).

\section{Results}

266 Table 4. Results of the K-mult test, for each bone.

\begin{tabular}{|l|l|l|}
\hline Bone & K & p-value \\
\hline Humerus & 0.75 & $<\mathbf{0 . 0 0 1}$ \\
\hline Radius-Ulna & 1.10 & $<\mathbf{0 . 0 0 1}$ \\
\hline Femur & 0.73 & $<\mathbf{0 . 0 0 1}$ \\
\hline Tibia & 0.79 & $<\mathbf{0 . 0 0 1}$ \\
\hline
\end{tabular}

There is a strong phylogenetic signal in all the bones studied (Table 4). That signal is lower than would be expected under a Brownian motion $(\mathrm{K}<1)$ for the humerus, the femur and the tibia. However, it is the reverse for the radius-ulna $(\mathrm{K}>1)$.

The results of the Student's t-test show no statistically significant difference of mean mass between species of different habitats in our sample (Fig. S6; Table S6), except for domesticated species that are heavier on average than mountainous species. However, this statistically significant difference of mean mass disappears when using a Benjamini-Hochberg correction (Table S6). 


\begin{tabular}{|c|c|c|c|c|c|c|c|c|c|c|c|c|}
\hline & \multicolumn{6}{|c|}{ MANCOVA } & \multicolumn{6}{|c|}{ PGLS } \\
\hline & \multicolumn{2}{|c|}{ Mass } & \multicolumn{2}{|c|}{ Habitat } & \multicolumn{2}{|c|}{ Interaction } & \multicolumn{2}{|c|}{ Mass } & \multicolumn{2}{|c|}{ Habitat } & \multicolumn{2}{|c|}{ Interaction } \\
\hline & $\mathrm{p}$ & $\mathrm{R}^{2}$ & $\mathrm{p}$ & $\mathrm{R}^{2}$ & $\mathrm{p}$ & $\mathrm{R}^{2}$ & $\mathrm{p}$ & $\mathrm{R}^{2}$ & $\mathrm{p}$ & $\mathrm{R}^{2}$ & $\mathrm{p}$ & $\mathrm{R}^{2}$ \\
\hline Humerus & $<0.001$ & 0.48 & $<0.001$ & 0.17 & 0.15 & 0.05 & $<0.001$ & 0.33 & $<0.01$ & 0.17 & 0.46 & 0.07 \\
\hline $\begin{array}{l}\text { Radius- } \\
\text { ulna }\end{array}$ & $<0.001$ & 0.50 & $<0.01$ & 0.14 & 0.16 & 0.07 & $<0.001$ & 0.15 & $<0.01$ & 0.22 & 0.51 & 0.10 \\
\hline Femur & $<0.001$ & 0.46 & $<0.001$ & 0.14 & 0.08 & 0.06 & $<0.001$ & 0.29 & $<0.001$ & 0.17 & 0.56 & 0.06 \\
\hline Tibia & $<0.001$ & 0.56 & 0.19 & 0.06 & 0.11 & 0.06 & $<0.001$ & 0.26 & 0.07 & 0.13 & 0.43 & 0.08 \\
\hline
\end{tabular}

Mass is statistically correlated with the shape of the bones in our sample, whether the test 278 used is a MANCOVA or a PGLS regression (see Table 5). According to the MANCOVA, mass 279 explains between $46 \%$ and $56 \%$ of the total variance of the shape of the bones. According to 280 the PGLS regression, this percentage is lower: between 15\% and 33\%. Habitat is statistically 281 correlated with the shape of each bone except the tibia (see Table 5). According to the 282 MANCOVA, habitat explains between $14 \%$ and $17 \%$ of the total shape variance, tibia excluded. 283 According to the PGLS, this percentage is slightly higher: between $17 \%$ and $22 \%$. The 284 interaction between mass and habitat never shows a statistically significant influence. 


\section{Humerus}
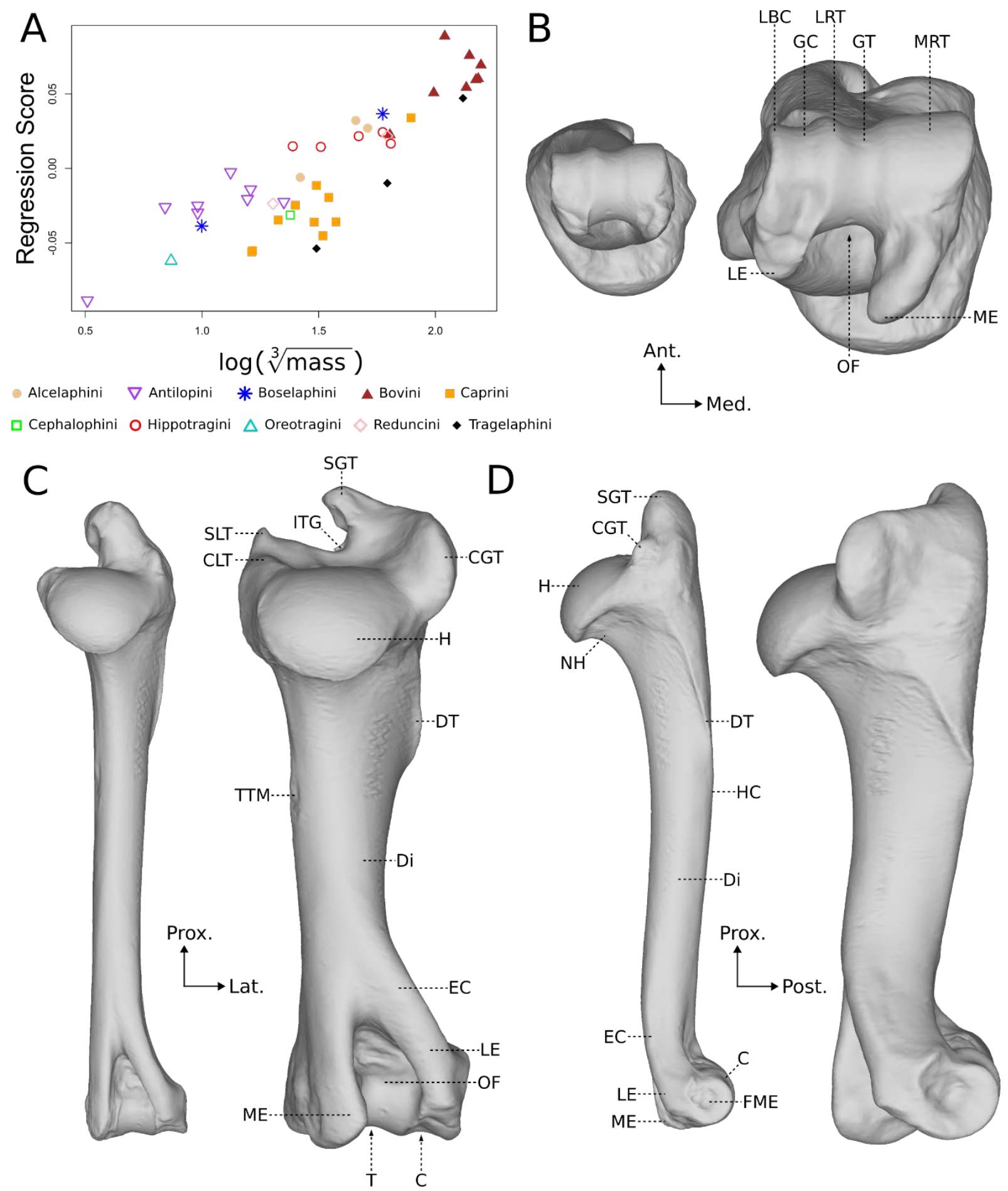

Figure 2. Results of the MANCOVA for the influence of the mass on the humerus. A: Regression score against the log of the cubic root of the mass of the species. B, C, D: TPS deformations of the humeri corresponding to maximal (right) and minimal (left) mass. Distal (B), posterior (C) and lateral (D) views. C: Capitulum; CGT: Convexity of the greater tuberosity; CLT: Convexity of the lesser tuberosity; Di: 
extensor digitorum lateralis; GC: Groove of the capitulum; GT: Groove of the trochlea; H: Head of the 294 humerus; HC: Humeral crest; ITG: Intertubercular groove; LBC: Lateral border of the capitulum; LE: 295 Lateral epicondyle; LRT: Lateral ridge of the trochlea; ME: Medial epicondyle; MRT: Medial ridge of 296 the trochlea; NH: Neck of the humerus; OF: Olecrannon fossa; SGT: Summit of the greater tuberosity; 297 SLT: Summit of the lesser tuberosity; T: Trochlea; TTM: Tuberosity of the teres major.

298 The graph of the regression score against the mean mass of the species (Fig. 2A) shows that 299 the tribes Caprini and Tragelaphini have a regression score that is on average below the other 300 tribes. This means that for a given mass, an average Caprini humerus would have features 301 reminiscent of that of a lighter species, compared to an average Antilopini humerus. The most 302 obvious shape difference due to a high mass in the humerus is the increase of the overall 303 robustness of the bone (Fig. 2B-D). The diameter of the diaphysis is relatively wider in bones 304 belonging to heavy species, and the bone is also slightly less curved in heavy species. The 305 convexity of the greater tuberosity is greatly enlarged. The lesser tuberosity is more developed, 306 extending more anteriorly and proximally. Its summit rises clearly above the head of the 307 humerus and its convexity is proportionally larger antero-posteriorly. The head of the humerus 308 is relatively wider in heavy species and the deltoid tuberosity is enlarged. The two epicondyles 309 are clearly symmetrical in humeri belonging to light species, whereas in heavy species the 310 medial epicondyle is much larger than the lateral one, expanding posteriorly and distally. The 311 epicondylar crest is more robust in heavy species. The medial ridge of the trochlea is relatively 312 wider latero-medially in heavier species, being almost as wide as half the trochlea whereas it is as wide as one third of the trochlea in lighter species. 

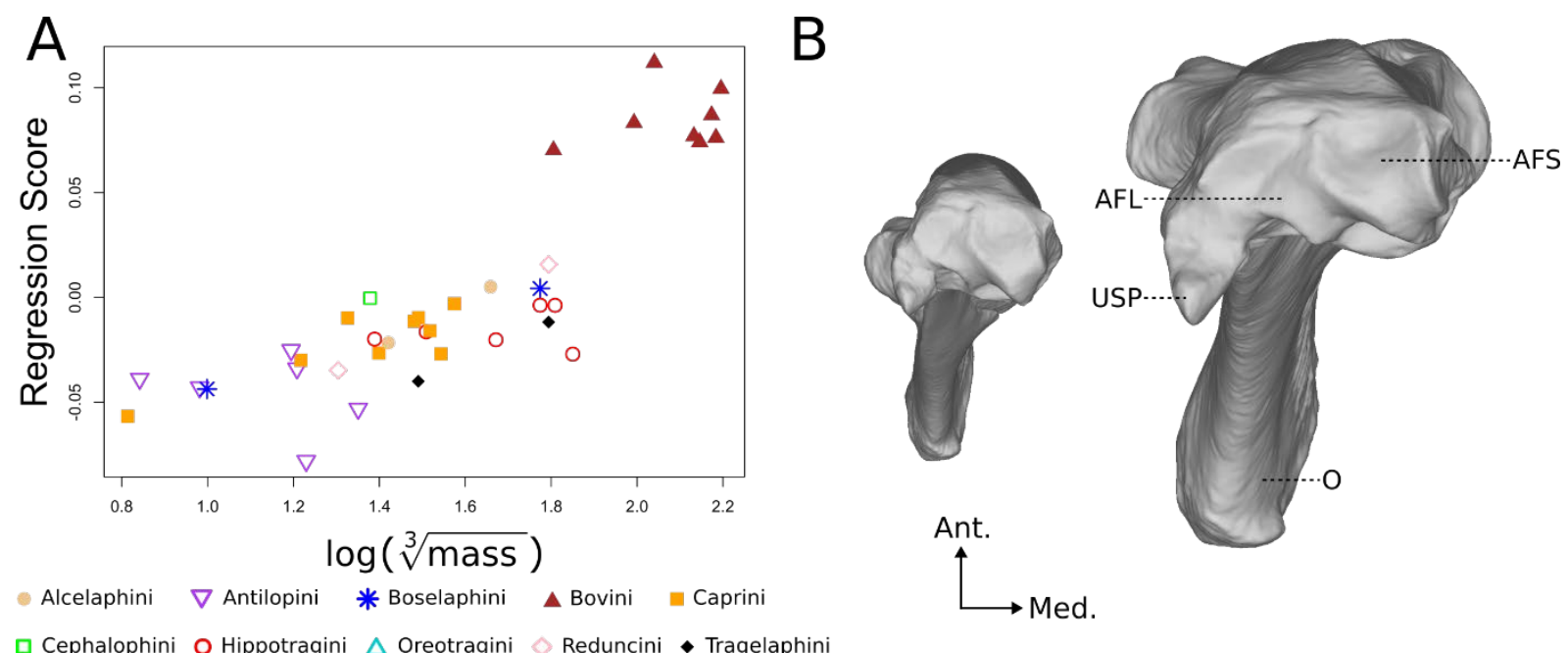

C

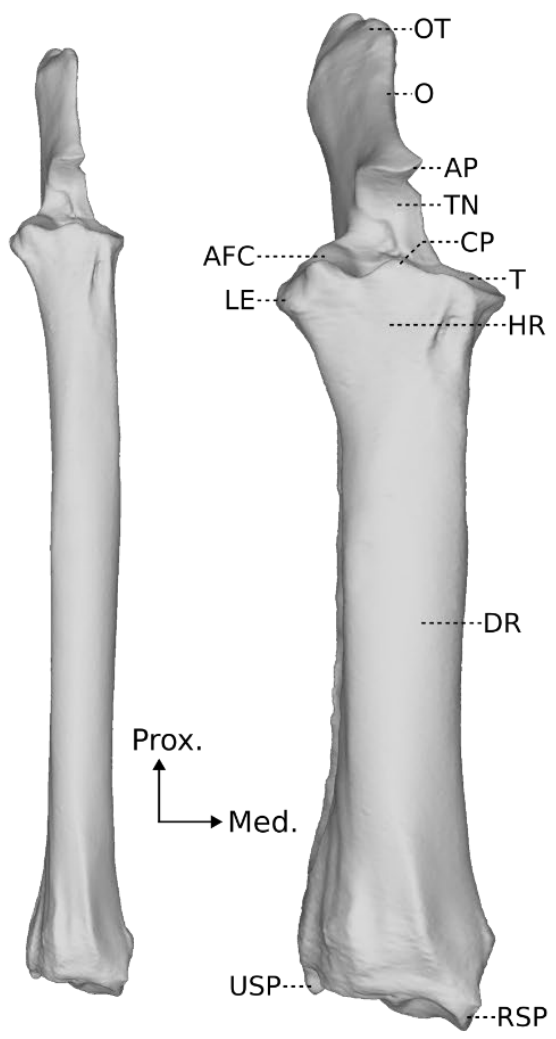

D

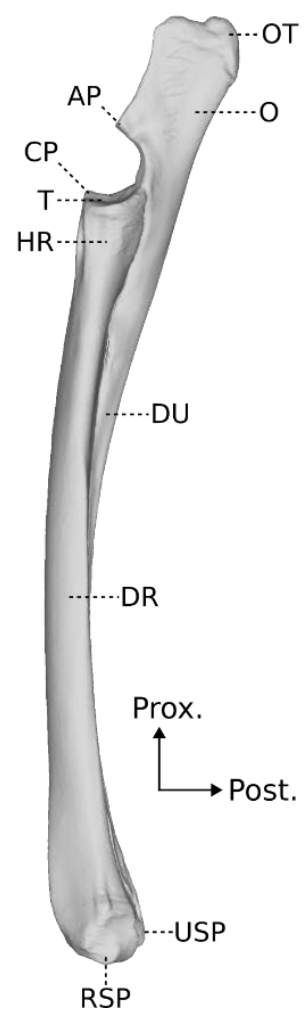

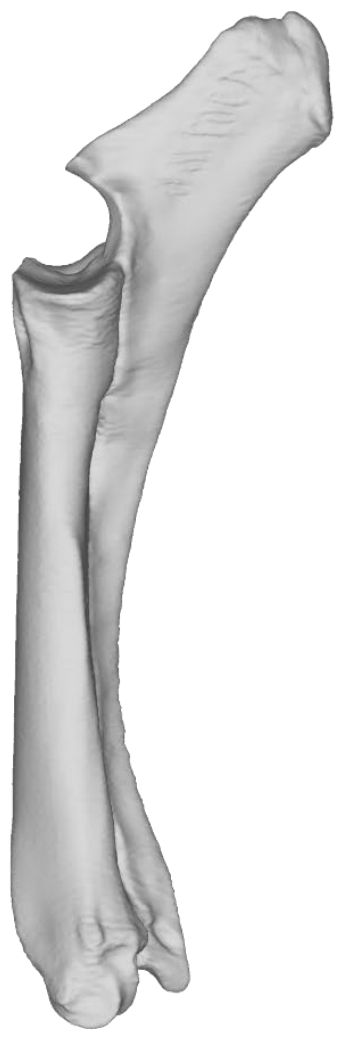

316 Figure 3. Results of the MANCOVA for the influence of the mass on the radius-ulna. A: Regression scores against the log of the cubic root of the mass of the species. B, C, D: TPS deformations of the radii-ulnae corresponding to maximal (right) and minimal (left) mass. Distal (B), anterior (C) and medial (D) views. AFC: Articular facet for the capitulum; AFL: Articular facet for the lunate; AFS: Articular facet for the scaphoid; AP: Anconeal process; CP: Coronoid process; DR: Diaphysis of the radius; DU: Diaphysis of the ulna; HR: Head of the radius; LE: Lateral eminence; O: Olecranon; OT: Olecranal tuber; RSP: Radial styloid process; T: Trochlea; TN: Trochlear notch; USP: Ulnar styloid process.

The regression plot (Fig. 3A) shows that the Bovini tribe members possess a much higher regression score than they would if they followed the same trend as the other tribes. This means 
325 that their radii-ulnae possess features that would be associated with a heavier mass than their 326 actual mass, if the regression were the same as for the other bovids. The opposite is observed 327 for two species of Antilopini (Litocranius walleri, and Nanger dama in a lesser extent), which 328 possess features associated with a lighter mass than their own. In heavier species (Figs. 3B-D), 329 the bones are more robust. The radius is relatively wider at midshaft. The shaft of the ulna is 330 antero-posteriorly wider in heavier species, whereas it is much reduced in lighter species, 331 especially in the distal half. The bones are more curved longitudinally in lighter species. The 332 olecranon is antero-posteriorly wider in heavier species, and oriented more obliquely, whereas 333 in light species the olecranon is oriented almost in the same axis as the diaphysis of the ulna, 334 forming a very open angle. The olecranon is also relatively longer proximo-distally in heavier 335 species, for a given bone length. The anterior parts of the articulatory facets for the lunate and 336 the scaphoid are both wider medio-laterally in heavier species. 

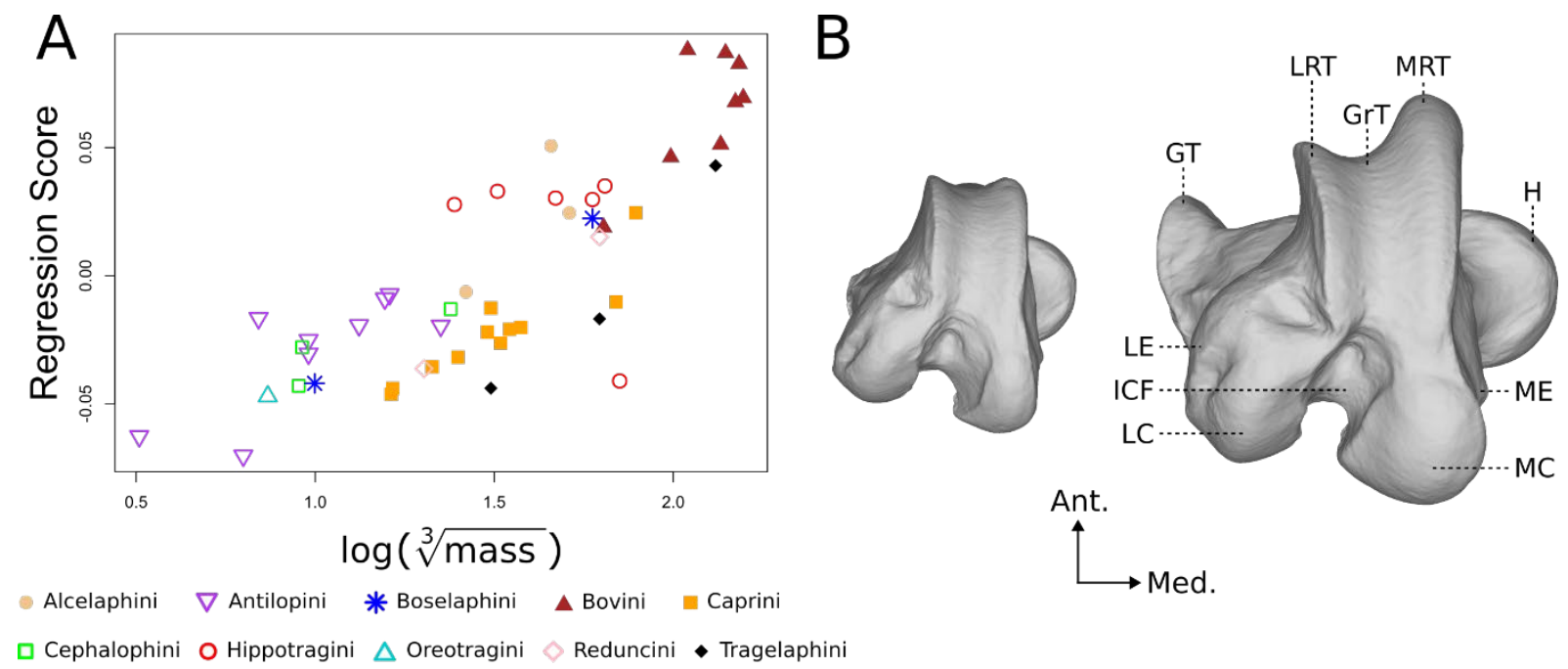

Cephalophini 0 Hippotragini $\triangle$ Oreotragini $\diamond$ Reduncini $\bullet$ Tragelaphin
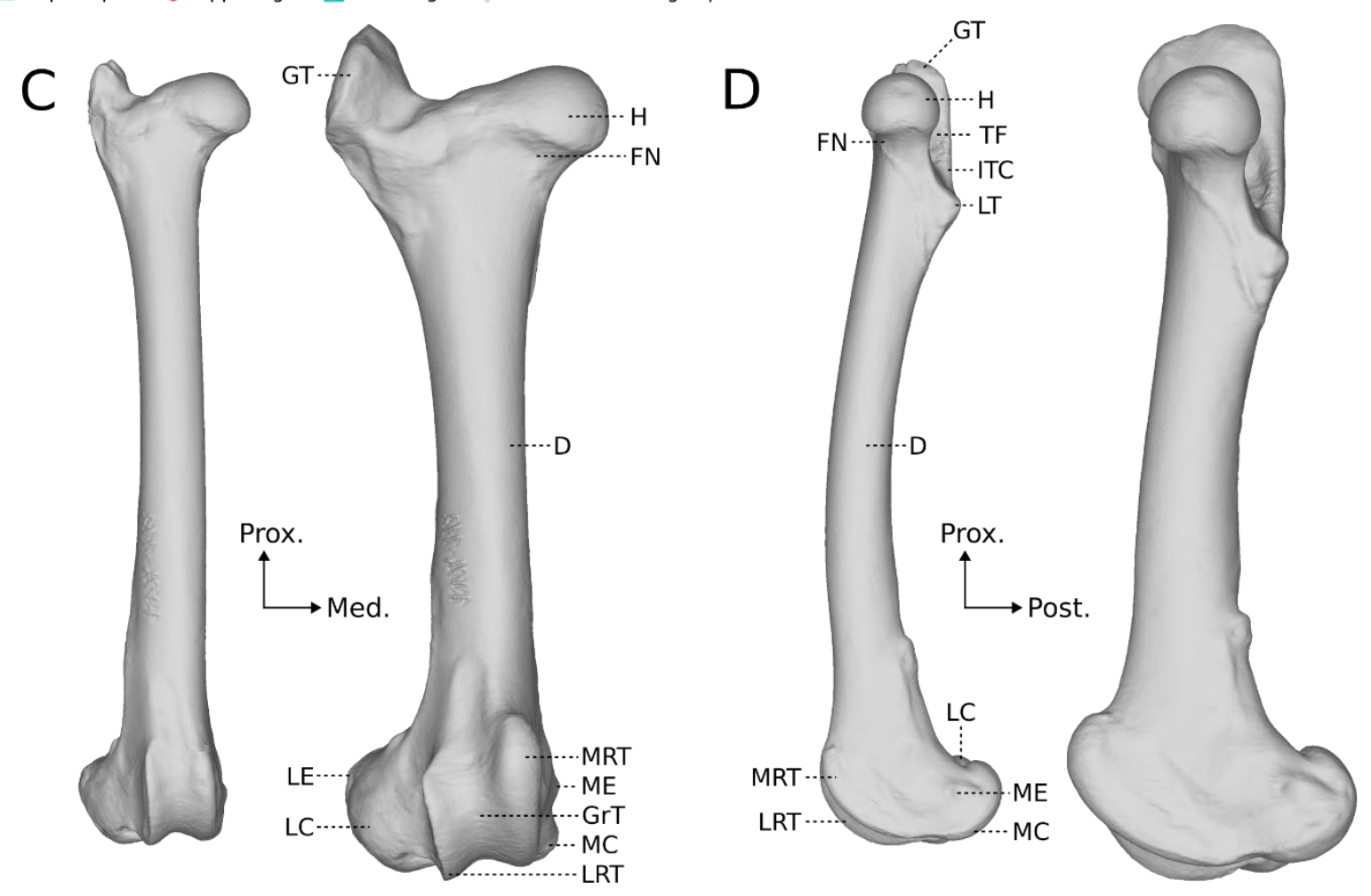

Figure 4. Results of the MANCOVA for the influence of the mass, on the femur. A: Regression score against the log of the cubic root of the mass of the species. B, C, D: TPS deformations of the femora corresponding to maximal (right) and minimal (left) mass. Distal (B), anterior (C) and medial (D) views. Di: Diaphysis; FN: Femoral neck; GrT: Grove of the trochlea; GT: Greater trochanter; H: Femoral head; ICF: Intercondylar fossa; ITC: Intertrochanteric crest; LC: Lateral condyle; LE: Lateral epicondyle; LRT: Lateral ridge of the trochlea; LT: Lateral tubercle; MC: Medial condyle; ME: Medial epicondyle; MRT: Medial ridge of the trochlea; TF: Trochanteric fossa.

The regression plot (Fig. 4A) shows again that the Caprini and Tragelaphini have a lower regression score than the other tribes, and thus present femora with more features associated to a light species than could be expected. One species of Hippotragini (Hippotragus niger) is very 
353 noticeably below the other members of its tribe; our sample for that species consist of only one 354 specimen with no collection number reported, it may have been misidentified. Femora 355 belonging to heavy bovids (Figs. 4B-D) display again more robust shafts and epiphyses. 356 Compared to what is observed for the other bones, the femoral epiphyses are particularly 357 enlarged in heavy species, showing a greater relative increase in their medio-lateral width than 358 the diaphysis does. The distal epiphysis is extended antero-posteriorly. The bone is more curved 359 longitudinally in light species. The greater trochanter is wider in all directions, rising well above 360 the head, in heavy species. There is no clear difference in the shape of the lesser trochanter. 361 Both supracondylar tuberosities are more marked in heavy species, and the supracondylar fossa 362 is deeper. The trochlea is almost symmetrical in light species, whereas the medial ridge is bigger 363 than the lateral one in heavy species, expanding anteriorly and proximally. It is also more 364 elongated antero-posteriorly in heavy species. Both condyles are wider medio-laterally in heavy 365 species, and the intercondylar fossa is consequently reduced. The lateral epicondyle is relatively 366 bigger in heavy species, forming a bump that is not present in lighter species 

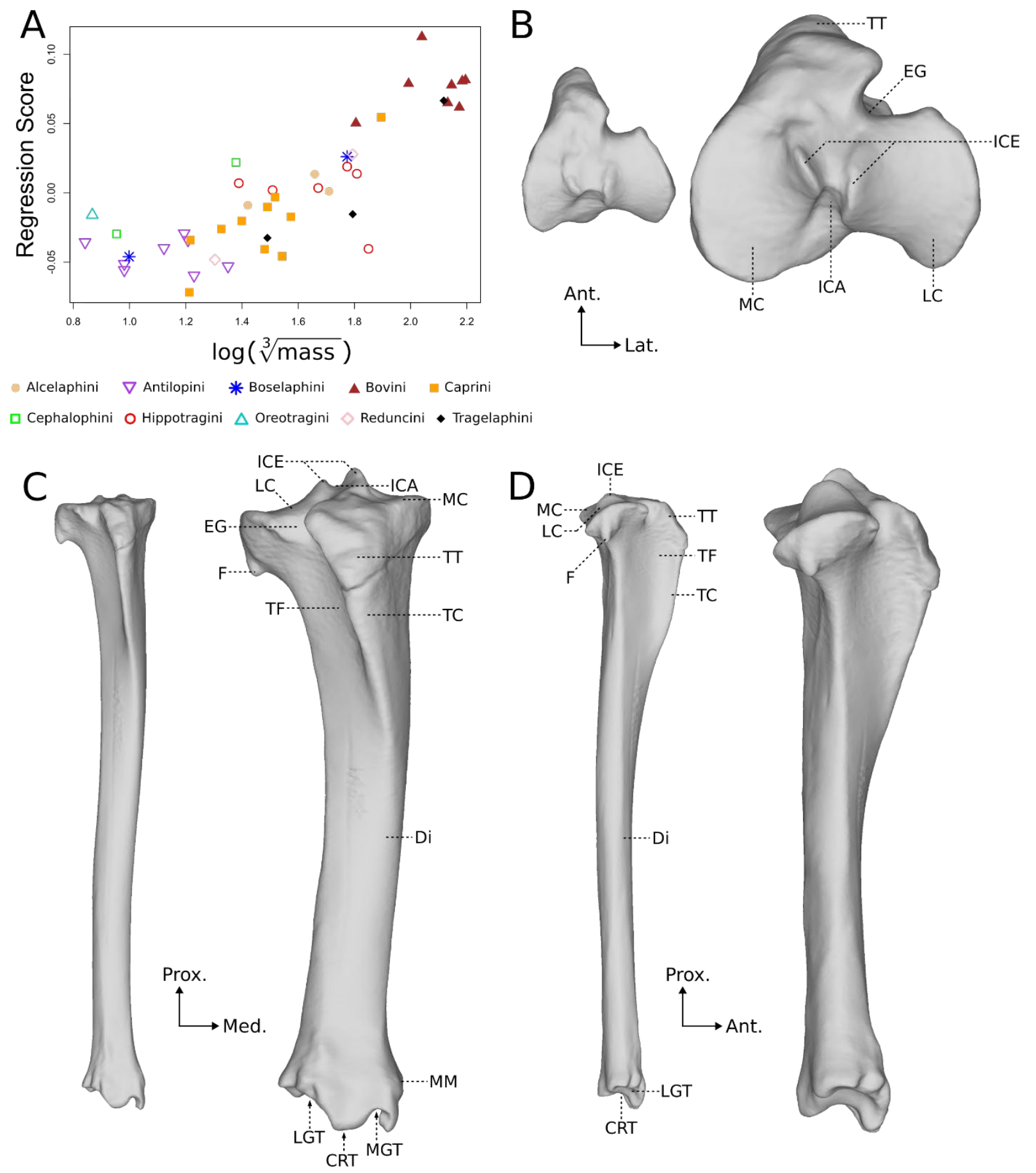

Figure 5. Results of the MANCOVA for the influence of the mass, on the tibia. A: Regression score against the log of the cubic root of the mass of the species. B, C, D: TPS deformations of the tibiae corresponding to maximal (right) and minimal (left) mass. Proximal (B), anterior (C) and lateral (D) views. CRT: Central ridge of the trochlea; Di: Diaphysis; EG: Extensor groove; F: Fibula; ICA: Intercondylar area; ICE: Intercondylar eminence; LC: Lateral condyle; LGT: Lateral groove of the trochlea; MC: Medial condyle; MGT: Medial groove of the trochlea; MM: Medial malleolus; TC: Tibial crest; TF: Tibial fossa; TT: Tibial tuberosity. 
The regression plot shows again the Bovini tribe with a higher regression score than what would be observed if they followed the same trend as the others (Fig. 5A). This is however less marked than for the radius-ulna, and this time two non-Bovini species (Ovibos moschatus,

379 Caprini, and Taurotragus oryx, Tragelaphini) have a regression score similar to that of the 380 Bovini. Please note that we could not analyse radii-ulnae for those two species, so it is 381 impossible to know if their radii-ulnae would display the same particularity. Tibiae belonging 382 to heavy species are, again, more robust overall, with relatively wider shaft and epiphyses (Fig. 383 5B-D). The condyles are larger medio-laterally and antero-posteriorly. The intercondylar 384 eminence rises higher proximally in heavy species than in light species. The groove for the 385 extensor muscle is deeper in heavy species. Both the tibial tuberosity and the tibial crest extend 386 more distally in heavy species, and are medio-laterally larger, more robust. The trochlea for the 387 astragalus remains symmetrical in both light and heavy species. 
388 Influence of habitat

389 Humerus
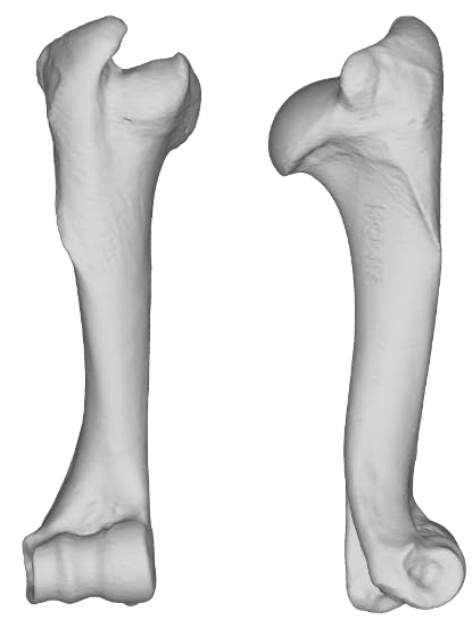

A - Open

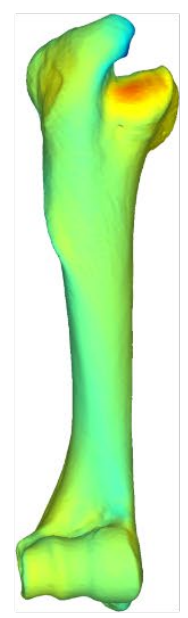

C - Heavy cover

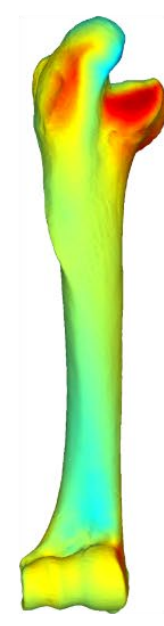

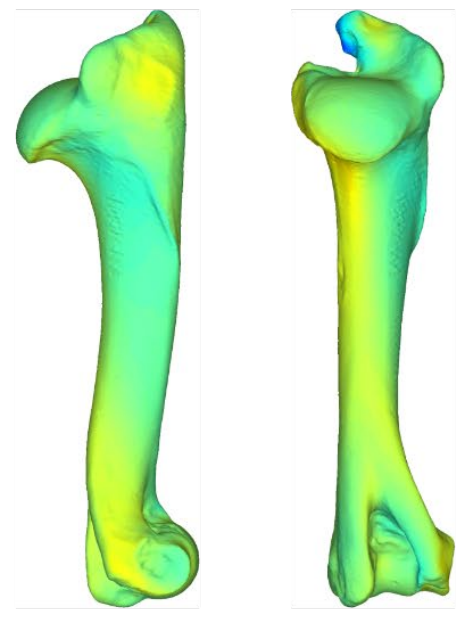

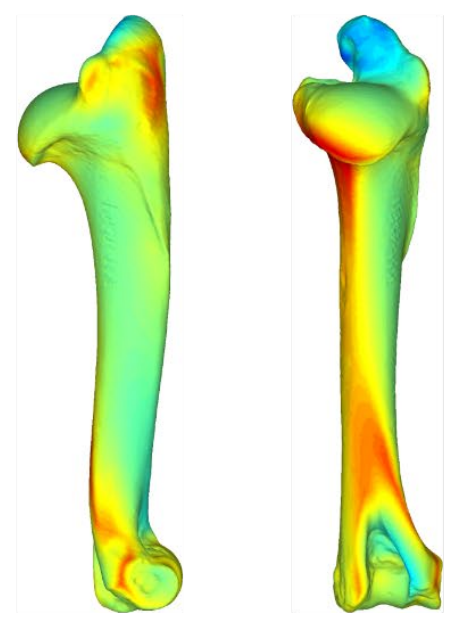

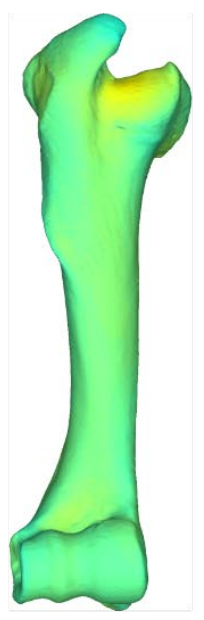

B - Light cover
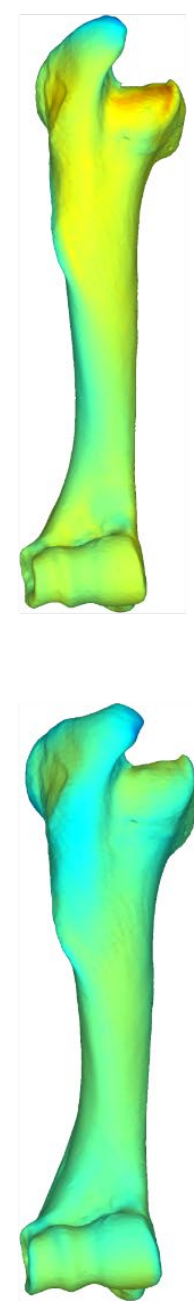

D - Forest
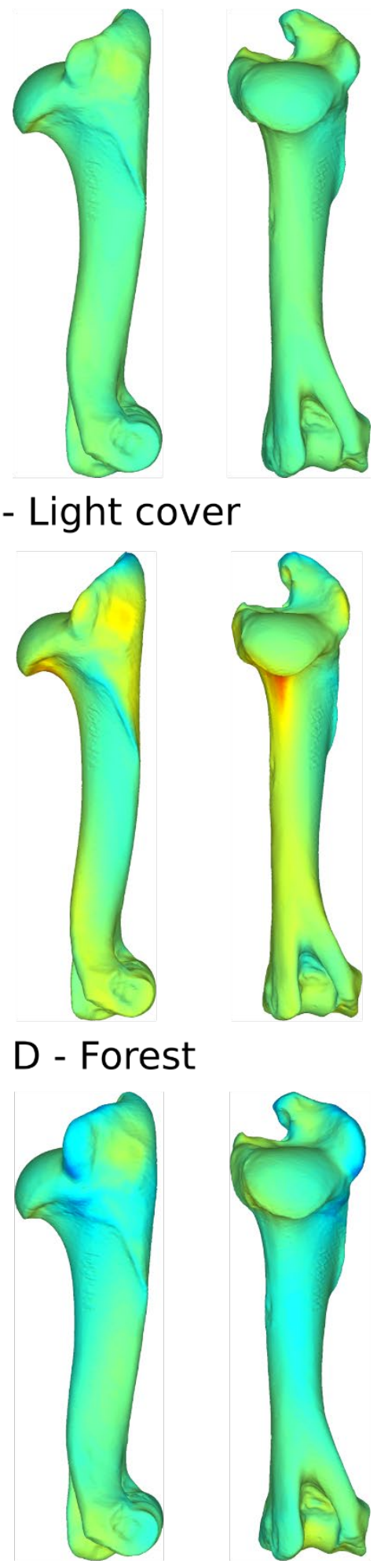

F - Domesticated

390

Negative deformation

Positive deformation 
391 Figure 6. TPS deformations of the humeri corresponding to each habitat category. The colours 392 represent the intensity of the local shape deviation between the represented habitat and open 393 habitat; open habitats are thus not coloured. Red denotes a positive deviation of the open habitat 394 compared to the represented habitat, blue a negative deviation, light-green an absence of 395 deviation. From left to right: anterior, lateral and posterior views.

396 The results on the humerus present a continuum of shapes is generally observed between 397 the habitat categories (Fig. 6), excluding domesticated species, with, from one extreme to the 398 other: open habitat species, light cover species, heavy cover species, forest species and 399 mountain species. The bone is generally slightly more robust along the diaphysis in open habitat 400 species than in mountain species. That difference is stronger for the epiphyses. The head of the 401 humerus is clearly wider relatively, especially medially and distally, in open and light cover 402 habitat species than in the others. The convexity of the greater tuberosity is larger in open habitat 403 species, the summit of the greater tuberosity rises higher proximally in mountain and forest 404 species than in the others. The lesser tuberosity rises higher proximally in open habitat species, 405 whereas it is on the same level as the head of the humerus in mountain species. It also expands 406 much more anteriorly in open and light cover habitat species than in mountain species, with 407 heavy cover and forest species in between. Distally, the trochlea is relatively larger in open and 408 light cover habitat species than in mountain habitat species. The epicondyles are also larger in 409 open habitat species, expanding in a medio-lateral axis. We note a slight asymmetry of the 410 epicondyles, with the medial epicondyle being larger, expanding especially posteriorly in all 411 habitats, except mountain habitats. Domesticated species present characteristics reminiscent of 412 heavy weight species, e.g. a relatively more robust bone, great development of the convexity of 413 the greater trochanter, and medial epicondyle larger than the lateral one. 
415 Radius-ulna

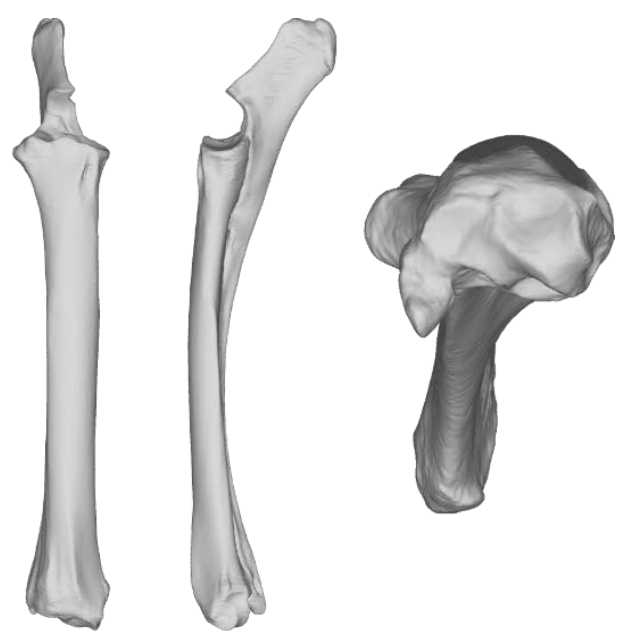

A - Open

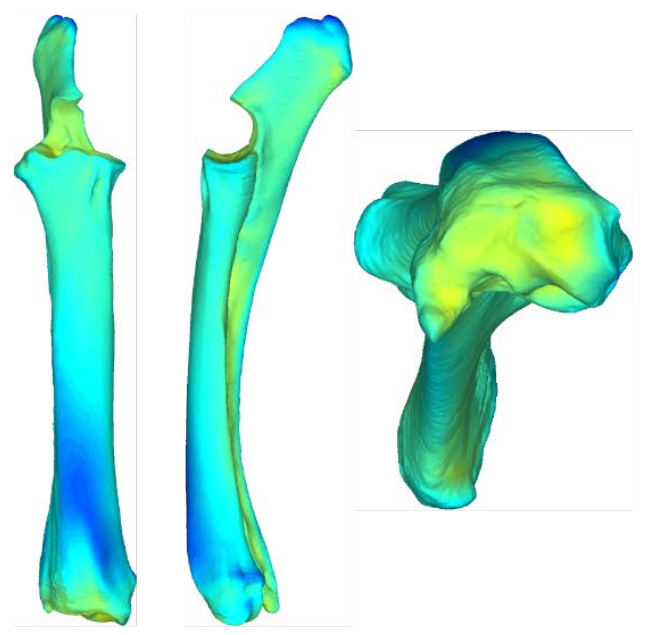

C - Heavy cover

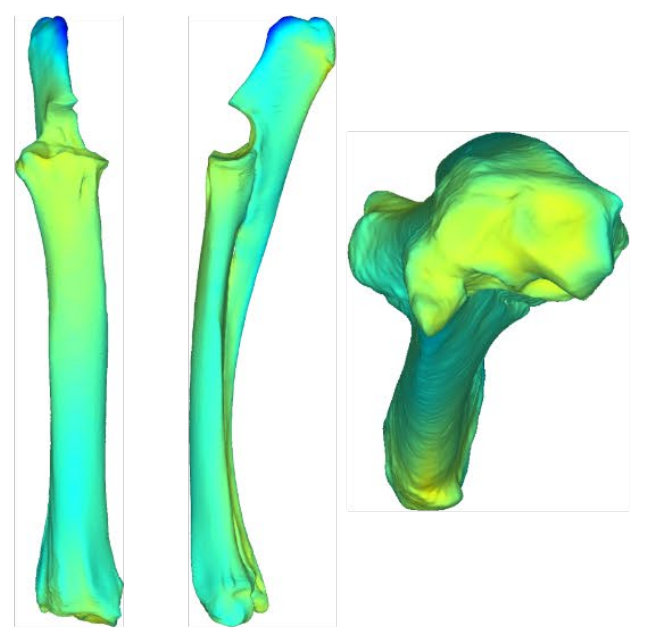

E - Mountain

Negative

416
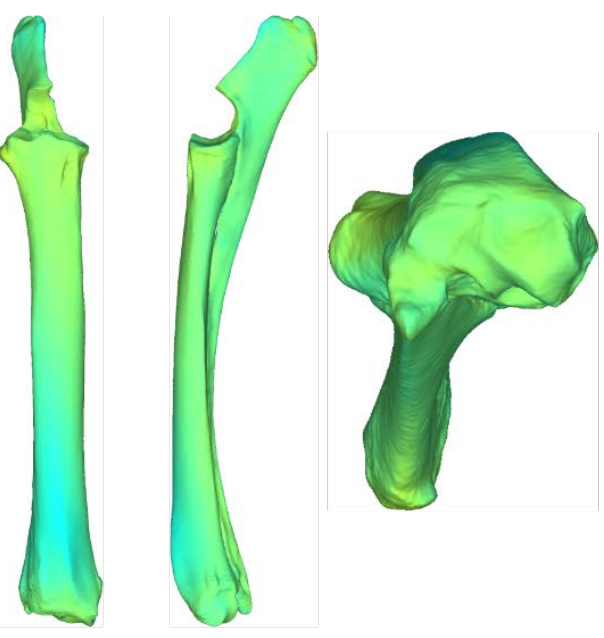

B - Light cover

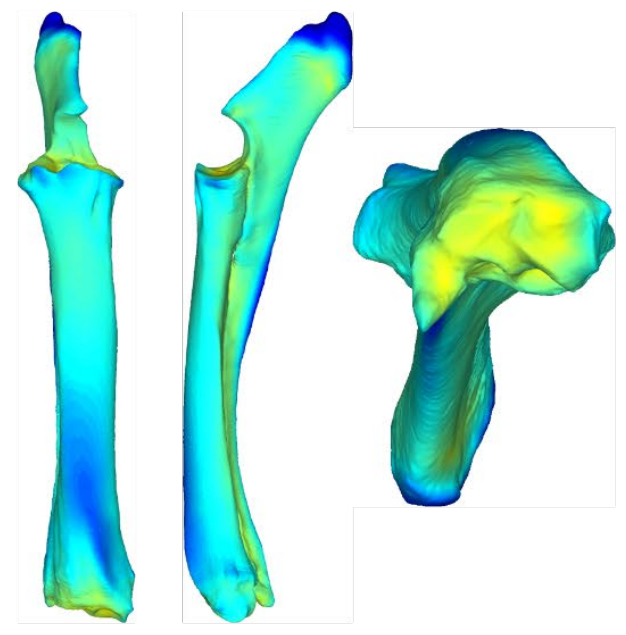

D - Forest

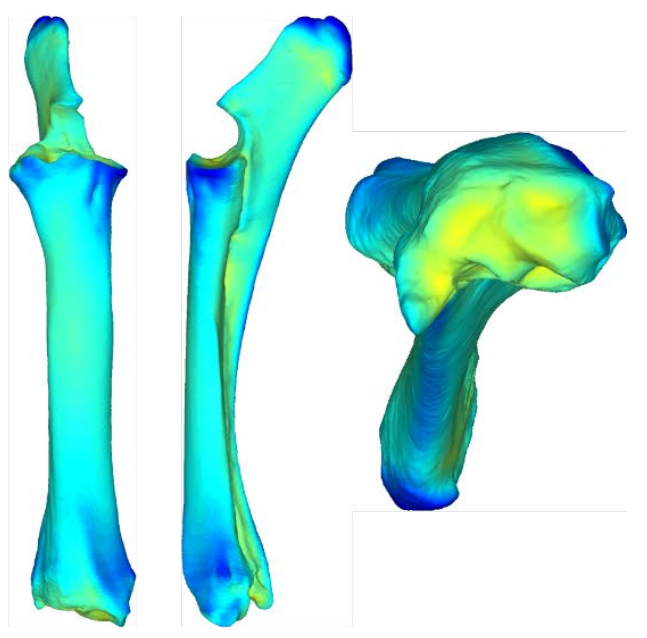

F - Domesticated

Positive deformation 
417 Figure 7. TPS representations of the radii-ulnae corresponding to each habitat category. The 418 colours represent the intensity of the local shape deviation between the represented habitat and 419 open habitat; open habitats are thus not coloured. Red denotes a positive deviation of the open 420 habitat compared to the represented habitat, blue a negative deviation, light-green an absence 421 of deviation. From left to right: anterior, medial and distal views.

422 For the radius-ulna, the bone is overall slightly more robust in heavy cover, forest and 423 domesticated species (Fig. 7). The olecranon has a different orientation depending on the habitat 424 of the species: the angle observed between the olecranon and the diaphysis of the ulna is more 425 open in mountain species than it is in all the other habitats. This very open angle is also observed 426 qualitatively in Oreotragus oreotragus, and thus it is not a characteristic of the Caprini tribe, 427 whose species constitute most of our sample of mountainous species. Please note that we did 428 not include this radius-ulna of $O$. oreotragus in our geometric morphometrics sample because 429 of damages to the articular facets for the carpus. The olecranon is relatively longer relative to 430 the total length of the bone in heavy cover, forest and domesticated species than it is in light 431 cover and open habitat species. The trochlea is medio-laterally wider in domesticated, forest 432 and heavy cover species than in the three other groups. No clear variation of shape is observed 433 for the articular facets with the carpus. 

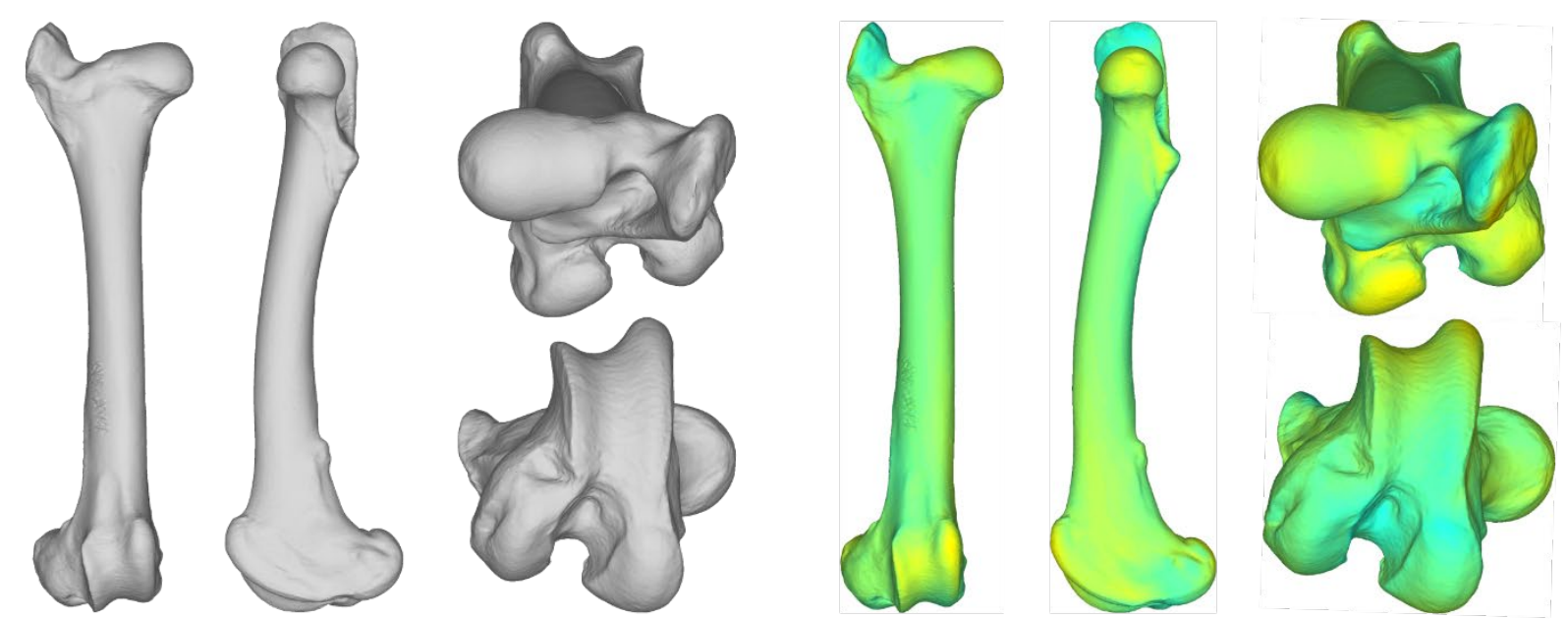

A - Open
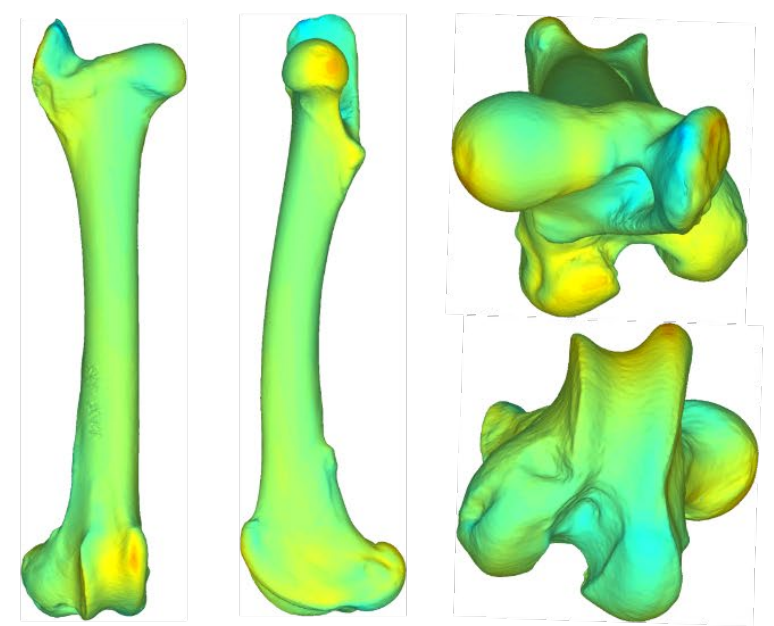

C - Heavy cover
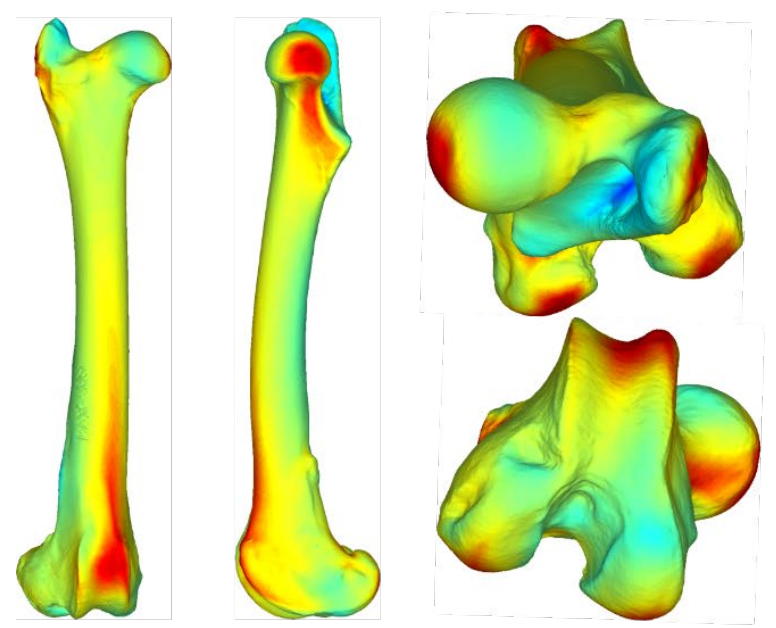

E - Mountain

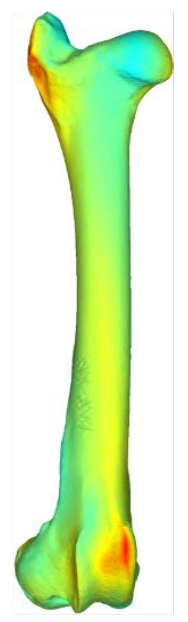

B - Light cover

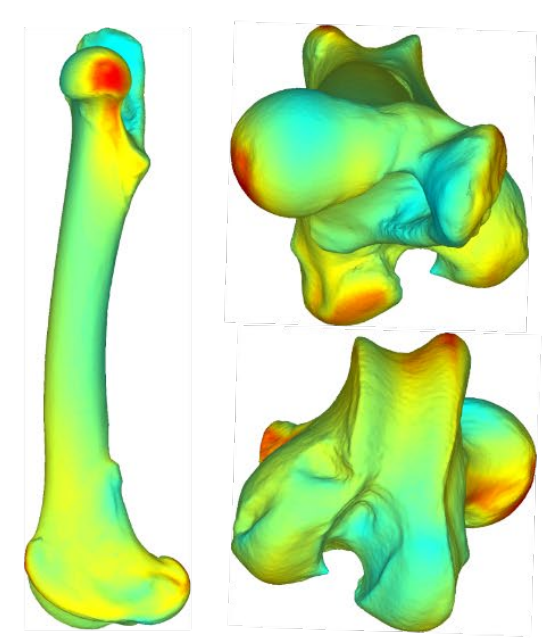

D - Forest
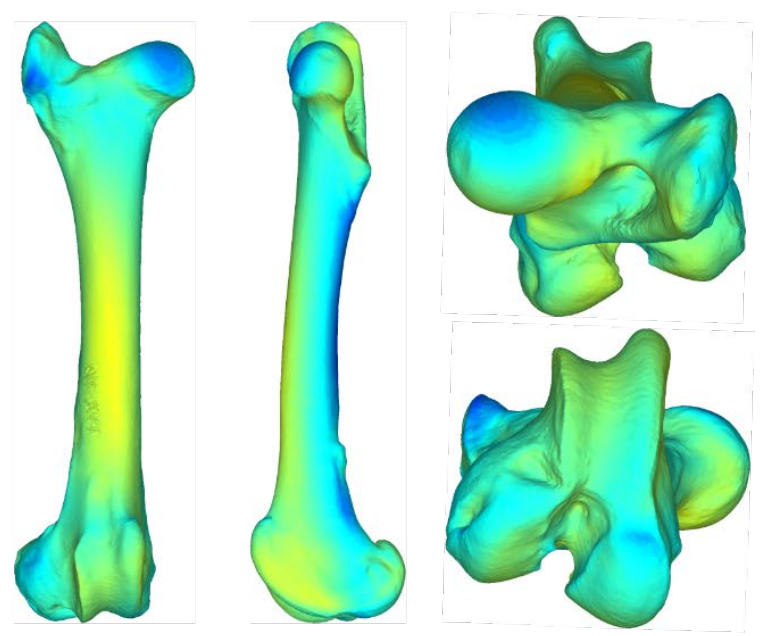

F - Domesticated

Negative

Positive deformation 
Figure 8. TPS representations of the femora corresponding to each habitat category. The colours represent the intensity of the local shape deviation between the represented habitat and open habitat; open habitats are thus not coloured. Red denotes a positive deviation of the open habitat compared to the represented habitat, blue a negative deviation, light-green an absence of deviation. From left to right and top to bottom: anterior, medial, proximal and distal views.

As for the humerus, a continuum of shape is generally observed for the femur between habitats (Fig. 8). From one extreme of the continuum to another, we find open habitat species, light cover species, heavy cover species, forest species and mountain species. Domesticated species do not place clearly on this continuum. The shaft has a very slightly wider diameter in open habitat species than in mountain species, and the bones are slightly more curved longitudinally. Both epiphyses are more robust in open habitat species; the proximal one is larger medio-laterally, and the distal epiphysis is much larger antero-posteriorly. The greater trochanter is larger in open habitat species, extending proximally and anteriorly; it is also wider latero-medially, especially in the lateral direction. The lesser trochanter presents no changes in shape with habitat. The head of the femur has the shape of a cylinder in open habitat species, positioned along a latero-medial axis; in mountain species however, it is clearly spherical. There is a clear asymmetry of the trochlea in open habitat species, the medial ridge being much wider medio-laterally than the lateral one; it is also expanding much more anteriorly. That asymmetry is gradually reducing in light cover, heavy cover and forest species and disappears entirely in mountain species, where both ridges have globally the same shape. There is no clear variation in the shape of the condyles, except that the medial condyle has a slightly more oblique orientation in open habitat species than in mountain species. Both condyles are, however, positioned more posteriorly in open habitat species, contributing to the antero-posterior extension of the epiphysis. Domesticated species have again characteristics reminiscent of heavier species, with a more robust bone, a relatively large greater trochanter and a strong asymmetry of the trochlea. They also present a round head of the femur, although not as round as mountain species.

\section{4}

\section{Discussion}

\section{Impact of phylogeny}

The K-mult tests are all significant, meaning that closely related species of our sample tend to show similar morphological traits in all their limb long bones. A K-mult value inferior to 1 means that there are less morphological similarities than expected under a Brownian evolution 
model, i.e. bone morphology is less restrained by phylogeny. This is what we observe for the humerus, the femur and the tibia, and is consistent with what is generally found in geometric morphometric studies of mammalian postcrania (e.g. Fabre et al., 2015; San Millán et al., 2015; Püschel and Sellers, 2016; Etienne et al., 2020; Lewton et al., 2020). A K-mult value above 1 means that there are more morphological similarities between closely related species than expected under a Brownian motion. This is what we observe for the radius-ulna. This could be explained by the stronger than usual shape differences observed between the Bovini tribe and the other bovids (Fig. 3A). One hypothesis is that the Bovini tribe underwent a rapid change of morphology for their radius-ulna, which would explain the high K-mult value for these bones.

\section{Adaptations to mass}

Mass has a strong influence on the shape of the sampled bones. It is clearly the strongest factor, whether using MANCOVA or PGLS regression. We note that the R-square is lower using PGLS however, meaning that a lot of the influence of the mass is linked to the phylogeny. Some monophyletic groups are indeed clearly characterized by a higher mass (e.g. Bovini, Hippotragini, Fig. 1). This is consistent with the fact that mass and size are often very strong factors influencing the shape of long bones and are thus expected to have a strong impact in morphometric studies (Hildebrand, 1982; Biewener, 1989; Polly, 2008; Klingenberg, 2016). In heavy species, we observe several likely adaptations such as an increase in the robustness of the bones, with a relatively wider shaft, which can help the bones resist to the heavy weight of their species by distributing the forces on a larger surface (Biewener, 1989; Currey, 2002). All bones show proportionally larger epiphyses in heavy species, allowing to sustain larger articular facets that permit a better dissipation of the more important forces, spreading them on a larger area again. Generally, a relative increase in the size of the muscle insertion area is observed, since proportionally stronger muscles are expected for animals of a greater weight (Alexander et al., 1981), although this is not uniform for all muscles. All bones, expect the tibia, are slightly curved in light species, but straighter in heavy species, as already observed in quadrupedal mammals in general (Bertram and Biewener, 1992). This could help the bones resist to bending stresses, by diminishing bending moments (Biewener, 1983).

\section{Forelimb}

More specifically, a strong enlargement is observed for the insertion areas of the extensor muscles of all three segments. Those are the most essential muscles to maintain the limb in an erect posture and thus the body in a standing position, and to propel the body forward (Barone, 
501 2010). In the shoulder, the supraspinatus inserts on the summits of the lesser and greater 502 tuberosities, which are both proportionally much larger in heavy species (Fig. 2C). The convexity of the greater tuberosity, where the infraspinatus attaches, is also extremely enlarged.

504 This muscle is not an extensor but has an important role for the stabilization of the shoulder, 505 which is most likely very important for heavy species, especially considering that large bovids 506 are said to carry most of their weight with their forelimbs (Scott, 1985).

507 For the forearm, the main extensor is the triceps. Accordingly, the olecranon as a whole, 508 where it inserts, is wider in heavier species especially in an antero-posterior direction, which is the direction of the forces exerted by the muscle (Fig. 3D). The origins of the triceps on the humerus are not particularly enlarged in heavy species, but the strongest head of the triceps originates on the scapula (Barone, 2010), so a stronger area of origin might be observed there. The olecranon is also longer when compared to the total length of the ulna, meaning that its efficiency as a lever arm must be increased in heavy species. Its more posterior orientation in heavy species would permit a more open angle when the elbow is in extension. This would increase the maximal stride length.

The extensors of the carpus and the digits also show a relatively enlarged insertion area on the humerus - the epicondylar crest - in heavy bovids (Fig. 2C). Again, this is most likely useful to accommodate a higher weight, which would tend to put the articulation in flexion, leading to the collapse of the animal if the weight were not counterbalanced by all the extensors.

Most flexors do not show such increase in robustness of their insertion areas. The main flexors of the arm are the teres major, the infraspinatus and the deltoideus (Barone, 2010). As mentioned above, the infraspinatus has a proportionally very enlarged insertion area on the humerus, but this is most likely due to its stabilization role more than its rather limited role as a flexor. The tuberosity of the teres major does not show any particular enlargement in heavy species (Fig. 2C). The lateral eminence of the radius, which serves as the insertion area of the biceps brachii, is not particularly more robust in heavier species. Contrary to the others, the flexors of the manus do show an increase in robustness of their areas of origin, particularly the medial epicondyle of the humerus (Fig. 2B), which is likely due to their different role. They act on the manus when it is on the ground, and thus must propel the body forward, whereas the flexors of the arm and forearm have no direct role in body propulsion (Barone, 2010). 
deltoid tuberosity is proportionally enlarged in heavy species (Fig. 2C), but much less than the tubercles, where the extensors insert. For the adductors, the insertion of the subscapularis on the convexity of the lesser tubercle is very robust in heavy species, but no particular increase in robustness is observed for the insertion of the teres major or the coracobrachialis. Stronger adductors and abductors could help stabilize the limb during locomotion, especially against medio-lateral movements. This could be important for heavy bovids, but not as important as limb extension, which seems to be reflected in the lesser increase in robustness observed in the insertion areas.

\section{$\underline{\text { Hindlimb }}$}

In the proximal hindlimb, the proportionally greatly enlarged greater trochanter observed in heavy species likely supports a very strong gluteus medius, which is the main muscle for keeping the hip in extension and is extremely important in propelling the whole body forward (Fig. 4C; Barone, 2010). The lesser trochanter does not show a particularly great enlargement in heavy species. It is mainly the insertion area of the illiacus and psoas magnus, which are flexors of the thigh; again, this seems to indicate that the flexors of heavy species do not need an increase of their strength as great as the extensors do. Several muscles performing various actions insert along the diaphysis of the femur, mainly the three vasti (lateralis, intermedius, medialis; extension), the adductores (adduction) and the pectineus (adduction, flexion and rotation). However, no change in shape is observed besides the increase of robustness of the diaphysis, even though the vasti are the main extensors of the knee and are expected to be very strong. Their very large insertion area most likely helps spread their important force along a greater surface, and thus the vasti may not necessitate an insertion as strong as other extensors.

More distally on the limb, another important muscle for the propulsion of the body is the gluteobiceps, inserting on the tibial crest, which is much enlarged in heavy species, as is the rest of the proximal epiphysis of the tibia (Fig. 5C). The antero-proximal tibia is also the main insertion area of the patellar ligaments, which transmit the force generated on the patella by a very powerful extensor of the knee, the quadriceps femoris (Barone, 2010). The semitendinosus and semimembranosus are also involved, although less strongly, in propulsion of the body. It is difficult to say if this leads to an increase of robustness of their insertion areas in heavy species, as they insert respectively on the diaphysis and the medial epicondyle, which are enlarged anyway to allow for better dissipation of the forces inside the bone and at the articulations. 
The insertion area of the gastrocnemius and the flexor superficialis (which is a flexor of the digits but an extensor of the pes; Barone, 2010), in the posterior and distal part of the femoral diaphysis, does show slightly stronger reliefs in heavy species, and the diaphysis is clearly enlarged in its distal part (Fig 4D). This could help sustain a stronger pull from those muscle that are essential to maintaining the limb upright, but could also be linked to the general enlargement of the tibiofemoral joint. An increase in robustness is observed in the lateral epicondyle of the femur, below which the extensor digitorum communis and the extensor digitorum medialis insert in the fossa extensoria. This could be due to an increase in strength from those muscles, which are flexors of the pes but extensor of the phalanges. It could also be a consequence of a probable increase in size of the lateral collateral ligament, which inserts precisely where the bump observed on the lateral epicondyle is located. Both these hypotheses are consistent with the overall need for a stronger articulation, firmly bound by ligaments and kept open by strong muscles when standing and moving.

\section{Differences in allometric trends}

Several differences in allometric trends were highlighted in our sample. One was observed on both stylopod bones, where for a given mass the Caprini and Tragelaphini tribes seem to have more gracile bones than the other tribes (Figs. 2A, 4A). Our sample of Tragelaphini consists of only three species, so that this trend remains to be confirmed, but our Caprini sample is the most extensive one (Table 1). These two tribes have little in common (Fig. 1); they are not particularly close phylogenetically, and do not share the same habitat, most Caprini living in a mountain habitat. This could imply that species living in a mountain habitat necessitate less robust bones (see Adaptations to habitat), or that the Caprini have naturally more gracile bones because of historic or structural constraints.

The radius-ulna of the Bovini displays an interesting allometric pattern, as it is more robust than expected if it followed the same allometric trend as that of the other tribes (Fig. 3A). To a lesser extent, this is also true for their tibia, as well as those of our heaviest Caprini and Tragelaphini (Ovibos moschatus and Taurotragus oryx, Fig. 5A). It is possible that in tribes or clades characterized by an important increase of mass (i.e. above approximately $300 \mathrm{~kg}$, Biewener, 1989), a shift in allometric trend of the zeugopodium convergently occurred at some point in their evolutionary history, enabling them to reach greater masses. Small and mediumsized mammals run with a more upright posture to increase the mechanical advantage of their musculoskeletal systems, and thus diminish the need for stronger muscles as mass increases 
(Biewener, 1989; Bertram and Biewener, 1992). Massive bovids of the Bovini tribe may have reached a point where they cannot run with more upright limbs, meaning this shift in allometric trend was necessary for body mass to increase further. This phenomenon has already been described in previous studies on mammals in general (Economos, 1983; Bertram and Biewener, 1990; Christiansen, 1999a, 1999b), and Bertram and Biewener (1992) do note that the radius and the tibia scale with particularly strong negative allometry for species above $200 \mathrm{~kg}$ in mean mass. Such potential shift in allometric trend is indeed not visible on the humerus nor on the femur of our sample. One possibility, as suggested by Scott (1985) is that the proximal segments of the limb are more constrained by the large amount of musculature inserting on them, and could be limited in their potential adaptive changes as compared to more distal segments. Specifically for the radius-ulna, it might have more importance in direct weight-bearing, due to being generally vertical when the animal is standing, aligned with the ground reaction force (Bertram and Biewener, 1992; see e.g. Fig. 9 in Castelló, 2016). All the other bones are more or less tilted, and thus support will be carried more by the muscles that will keep the joints in extension.

\section{Adaptations to habitat}

Habitat has a significant impact on the shape of the bones except the tibia, even when taking the phylogenetic history into account. Shape variations are however more subtle than those linked to body mass. A gradation is observed between the different habitats, especially on the stylopod bones, along a gradient from open habitat to mountain habitat. This suggest that habitat would be better represented as a continuum, with on one end open habitats, where running as fast as possible is the main predator-avoidance strategy and where there is little need for manoeuvrability, and on the other end closed or mountain habitats, where manoeuvrability is essential in order not to trip and fall over when running (Jarman, 1974; Kappelman, 1988).

Specifically, for the forelimb, in open habitat species we note adaptations for more stable articulations, able to sustain a greater force passing through linked to the high frequency of galloping in these species. This is especially observable on the humerus whose head and trochlea are wider in all directions (Fig. 6). On the medial epicondyle of the humerus, a larger insertion area for the flexors of the digits is observed in open habitat species. Presumably stronger flexors allow a greater propulsion that may be necessary for species galloping frequently, but not for mountain-adapted species since they do not need to gallop as often. The very posterior orientation of the olecranon observed in open habitat species allows a more 
important extension of the forearm, and thus an increase in stride length during galloping, which in turn leads to increased speed.

As for the hindlimb, the larger epiphyses in open habitat species can again be explained by a need for a greater force to pass through. The larger greater trochanter can, as for species with an important mass, permit a greater force to come from the gluteus medius and thus a more powerful propulsion of the body (Fig. 8; Barone, 2010). The cylindrical shape of the femoral head restricts movement in a parasagittal plane and stabilizes the hip joint (Kappelman, 1988; Kappelman et al., 1997). Forest species present a very round femoral head, improving the freedom of movement of their hip (i.e. abduction, adduction and rotation), which is necessary to move in a complex system of bushes and roots. Mountain species present an even rounder femoral head than forest species, illustrating the very large range of motion needed to navigate in mountain habitats. Our femur sample of mountain species contains only two species that are not part of the Caprini tribe (D. megalotis and O. oreotragus) but that present the same set of presumed adaptations to a mountain habitat as Caprini species, indicating that they are not specific to the Caprini. The asymmetry of the femoral trochlea observed in open habitat species could help stabilize the stifle joint during locomotion, by preventing the medial dislocation of the patella (Janis et al., 2012). Interestingly, this asymmetry is also present in forest and heavy cover species, being only totally absent in mountain species. The antero-posterior extension of the trochlea observed in those same species could increase the moment arm of the stifle joint, and thus allow the leg to perform its propulsion role more efficiently. The femur overall presents many characteristics that can link its morphology to the habitat occupied by the species, which confirms that it is an excellent bone in order to reconstruct paleoenvironments in bovids.

Domesticated species generally present traits similar to those of heavier species. It is the only habitat category in our sample that could have a significantly higher mean mass than another category (mountain habitat, Fig. S6; Table S6). They might therefore be indeed slightly heavier on average, which would explain their bone morphology. Alternatively, domesticated species could have sustained a selective pressure for an increased amount of meat, i.e. larger muscles. It is possible that this increase in muscle volume resulted in a need for stronger bones.

\section{Concomitant influences of mass and habitat}

Species living in open habitats and species having a high body mass present some similarities in the morphology of their limb long bones. Most notably, they share larger epiphyses, larger tuberosities and a larger medial epicondyle on the humerus, an enlarged 
661 greater trochanter and an asymmetric trochlea on the femur. Considering open habitat species 662 do not have a significantly higher mass than the others species in our sample (Fig. S6; Table 663 S6), this could be due to the higher forces involved when needing to attain a greater speed or 664 move a greater mass. As a consequence, these similar anatomical features convergently result 665 from different selective pressures, which might make it difficult to decipher the paleobiology 666 of extinct species.

\section{Conclusion}

668 We provided here the first 3D geometric morphometric study focusing on the long bones of bovids. Our results confirm that mass and to a lesser extent habitat strongly influence the shape of stylopod and zeugopod bones, even when taking into account the phylogeny. Bones of heavier species tend to be more robust, capable of resisting to the higher forces generated by their own weight and their muscles' contractions. The insertion areas of the muscles that have to either support the weight of the body or propel it forward (i.e. the extensors of all the limb segments, and the flexors of the manus and of the digits of the hindlimb) show a greater increase in proportional size than those of muscles mostly acting on the limb during the swing phase. A continuum of shape is observed from open habitats to mountain habitats, going through light cover, heavy cover and forest habitats. Open habitat species present clear adaptations for increased cursoriality, more robust articulations and stronger insertion areas for the muscles that propel the limb. Mountain and forest species present adaptations for manoeuvrability, useful for navigating in a forest or on a cliff. The degree of complexity of the substrate of a particular habitat (e.g. the flat substrate of a grassland vs. the steep terrain of a mountain or the network of roots and bushes of a forest), and the different predator-avoidance strategies it implies, seems to be a very important environmental metric influencing the shape of long bones in bovids. Overall, it seems that bovids present a much conserved long bone morphology across their entire family, with relatively little variation in shape, which makes it easy to identify variations linked to mass or habitat. Our study helped clarify with precision how long bone shape can adapt to an increase in mass or a change of habitat in ungulates. It opens new perspectives of research, for instance on how to describe more precisely shifts in allometric trends and associated shape variations, or on microanatomical studies to correlate internal architecture with the morphology of muscle insertion areas. 
692 We wish to warmly thank the curators of the collections where we digitized specimens: $\mathbf{J}$.

693 Lesur, C. Bens, \& A. Verguin (Muséum National d'Histoire Naturelle, Paris, France) and S.

694 Bock (Museum für Naturkunde, Berlin, Germany). We acknowledge the very helpful comments

695 of two anonymous reviewers that allowed us to improve the quality of our manuscript. This

696 work acknowledges financial support from ERC-2016-STG GRAVIBONE allocated to A.

697 Houssaye.

698 Author Contribution

699 C. Etienne designed the experiments, participated in data analyses and interpretation, wrote the 700 manuscript, and approved the final draft. A. Filippo digitized all the specimens, reviewed the 701 manuscript, and approved the final draft. R. Cornette designed the experiments, participated in 702 data analyses and interpretation, reviewed the manuscript, and approved the final draft. A. 703 Houssaye designed the experiments, participated in data analyses and interpretation, reviewed 704 the manuscript, and approved the final draft.

\section{References}

706

707

708

709

710

711

712

713

714

715

716

717

718

719

720

721

722

723

724

725

726

727

728

729

730
Adams, D., Rohlf, F.J., Slice, D., 2013. A Field Comes of Age: Geometric Morphometrics in the 21st Century. Hystrix 24, 7-14. https://doi.org/10.4404/hystrix-24.1-6283

Adams, D.C., 2014a. A Generalized K Statistic for Estimating Phylogenetic Signal from Shape and Other High-Dimensional Multivariate Data. Syst Biol 63, 685-697. https://doi.org/10.1093/sysbio/syu030

Adams, D.C., 2014b. A Method for Assessing Phylogenetic Least Squares Models for Shape and Other High-Dimensional Multivariate Data. Evolution 68, 2675-2688. https://doi.org/10.1111/evo.12463

Adams, D.C., Collyer, M., Kaliontzopoulou, A., Sherratt, E., 2018. Geomorph : Geometric morphometric analyses for 2D/3D data.

Agisoft LLC, 2017. Agisoft PhotoScan Professional.

Alexander, R.M., Jayes, A.S., Maloiy, G.M.O., Wathuta, E.M., 1981. Allometry of the leg muscles of mammals. Journal of Zoology 194, 539-552. https://doi.org/10.1111/j.1469-7998.1981.tb04600.x

Artec 3D, 2018. Artec Studio Professional.

Barone, R., 2010. Anatomie comparée des mammifères domestiques. Tome 2 : arthrologie et myologie, 4ème édition. ed. Vigot Frères, Paris.

Barone, R., 1999. Anatomie comparée des mammifères domestiques. Tome 1: ostéologie, 5ème édition. ed. Vigot Frères, Paris.

Barr, W.A., 2014. Functional morphology of the bovid astragalus in relation to habitat: controlling phylogenetic signal in ecomorphology. J. Morphol. 275, 1201-1216. https://doi.org/10.1002/jmor.20279

Benjamini, Y., Hochberg, Y., 1995. Controlling the False Discovery Rate: A Practical and Powerful Approach to Multiple Testing. Journal of the Royal Statistical Society: Series B (Methodological) 57, 289-300. https://doi.org/10.1111/j.2517-6161.1995.tb02031.x 
Bertram, J.E.A., Biewener, A., 1990. Differential scaling of the long bones in the terrestrial carnivora and other mammals. Journal of Morphology 204, 157-169. https://doi.org/10.1002/jmor.1052040205

Bertram, J.E.A., Biewener, A.A., 1992. Allometry and curvature in the long bones of quadrupedal mammals. Journal of Zoology 226, 455-467. https://doi.org/10.1111/j.1469-7998.1992.tb07492.x

Bibi, F., 2013. A multi-calibrated mitochondrial phylogeny of extant Bovidae (Artiodactyla, Ruminantia) and the importance of the fossil record to systematics. BMC Evolutionary Biology 13, 166. https://doi.org/10.1186/1471-2148-13-166

Biewener, A., 1989. Mammalian Terrestrial Locomotion and Size. BioScience 39, 776-783. https://doi.org/10.2307/1311183

Biewener, A., Patek, S., 2018. Animal Locomotion, 2nd edition. ed. Oxford University Press, New York.

Biewener, A.A., 2005. Biomechanical consequences of scaling. Journal of Experimental Biology 208, 1665-1676. https://doi.org/10.1242/jeb.01520

Biewener, A.A., 1983. Allometry of quadrupedal locomotion: the scaling of duty factor, bone curvature and limb orientation to body size. Journal of Experimental Biology 105, 147-171.

Blomberg, S.P., Garland, T., Ives, A.R., 2003. Testing for phylogenetic signal in comparative data: behavioral traits are more labile. Evolution 57, 717-745.

Botton-Divet, L., Cornette, R., Fabre, A.-C., Herrel, A., Houssaye, A., 2016. Morphological Analysis of Long Bones in Semi-aquatic Mustelids and their Terrestrial Relatives. Integrative and Comparative Biology 56, 1298-1309. https://doi.org/10.1093/icb/icw124

Cabin, R.J., Mitchell, R.J., 2000. To Bonferroni or Not to Bonferroni: When and How Are the Questions. Bulletin of the Ecological Society of America 81, 246-248.

Castelló, J.R., 2016. Bovids of the World: Antelopes, Gazelles, Cattle, Goats, Sheep, and Relatives. Princeton University Press, Princeton and Oxford.

Christiansen, P., 1999a. Scaling of mammalian long bones: small and large mammals compared. Journal of Zoology 247, 333-348. https://doi.org/10.1111/j.14697998.1999.tb00996.x

Christiansen, P., 1999b. Scaling of the limb long bones to body mass in terrestrial mammals. J. Morphol. 239, 167-190. https://doi.org/10.1002/(SICI)10974687(199902)239:2<167::AID-JMOR5>3.0.CO;2-8

Cignoni, P., Callieri, M., Corsini, M., Dellepiane, M., Ganovelli, F., Ranzuglia, G., 2008. MeshLab: an Open-Source Mesh Processing Tool. Proceedings of the 2008 Eurographics Italian Chapter Conference 129-136.

Curran, S.C., 2018. Three-dimensional geometric morphometrics in paleoecology, in: Croft, D., Su, D., Simpson, F. (Eds.), Methods in Paleoecology: Reconstructing Cenozoic Terrestrial Environments and Ecological Communities, Vertebrate Paleobiology and Paleoanthropology Series. Springer, Cham, pp. 319-337.

Curran, S.C., 2012. Expanding ecomorphological methods: geometric morphometric analysis of Cervidae post-crania. Journal of Archaeological Science 39, 1172-1182. https://doi.org/10.1016/j.jas.2011.12.028

Currey, J.D., 2002. Bones: Structure and Mechanics. Princeton University Press.

De luliis, G., Pulerà, D., 2011. The Dissection of Vertebrates, 2nd edition. ed. Academic Press.

DeGusta, D., Vrba, E., 2003. A method for inferring paleohabitats from the functional morphology of bovid astragali. Journal of Archaeological Science 30, 1009-1022. https://doi.org/10.1016/S0305-4403(02)00286-8

Doube, M., Conroy, A.W., Christiansen, P., Hutchinson, J.R., Shefelbine, S., 2009. ThreeDimensional Geometric Analysis of Felid Limb Bone Allometry. PLOS ONE 4, e4742. https://doi.org/10.1371/journal.pone.0004742

Dunn, R.H., 2018. Functional Morphology of the Postcranial Skeleton, in: Croft, D., Su, D., Simpson, F. (Eds.), Methods in Paleoecology: Reconstructing Cenozoic Terrestrial 
801

802

803

804

805

806

807

808

809

810

811

812

813

814

815

816

817

818

819

820

821

822

823

824

825

826

827

828

829

830

831

832

833

834

835

836

837

838

Environments and Ecological Communities, Vertebrate Paleobiology and Paleoanthropology Series. Springer, Cham, pp. 23-36.

Economos, A.C., 1983. Elastic and/or geometric similarity in mammalian design? Journal of Theoretical Biology 103, 167-172. https://doi.org/10.1016/0022-5193(83)90206-0

Etienne, C., Mallet, C., Cornette, R., Houssaye, A., 2020. Influence of mass on tarsus shape variation: a morphometrical investigation among Rhinocerotidae (Mammalia: Perissodactyla). Biol J Linn Soc. https://doi.org/10.1093/biolinnean/blaa005

Fabre, A.-C., Cornette, R., Goswami, A., Peigné, S., 2015. Do constraints associated with the locomotor habitat drive the evolution of forelimb shape? A case study in musteloid carnivorans. Journal of Anatomy 226, 596-610. https://doi.org/10.1111/joa.12315

Goolsby, E.W., 2015. Phylogenetic Comparative Methods for Evaluating the Evolutionary History of Function-Valued Traits. Syst Biol 64, 568-578. https://doi.org/10.1093/sysbio/syv012

Gunz, P., Mitteroecker, P., 2013. Semilandmarks: a method for quantifying curves and surfaces. Hystrix It. J. Mamm. 24, 103-109. https://doi.org/10.4404/hystrix-24.1-6292

Gunz, P., Mitteroecker, P., Bookstein, F.L., 2005. Semilandmarks in Three Dimensions, in: Slice, D. (Ed.), Modern Morphometrics in Physical Anthropology, Developments in Primatology: Progress and Prospects. Springer, Boston, pp. 73-98. https://doi.org/10.1007/0-387-27614-9_3

Hall, B.K., 2008. Fins into Limbs: Evolution, Development, and Transformation. University of Chicago Press, Chicago.

Hildebrand, M., 1982. Analysis of Vertebrate Structure, 2ème édition. ed. Wiley, New York.

Hildebrand, M., Bramble, D.M., Liem, K.F., Wake, D., 1985. Functional Vertebrate Morphology. Belknap Press of Harvard University Press, Cambridge, USA.

Janis, C.M., Shoshitaishvili, B., Kambic, R., Figueirido, B., 2012. On their knees: distal femur asymmetry in ungulates and its relationship to body size and locomotion. Journal of Vertebrate Paleontology 32, 433-445. https://doi.org/10.1080/02724634.2012.635737

Jarman, P.J., 1974. The Social Organisation of Antelope in Relation to Their Ecology. Behaviour 48, 215-267.

Kappelman, J., 1991. The paleoenvironment of Kenyapithecus at Fort Ternan. Journal of Human Evolution 20, 95-129. https://doi.org/10.1016/0047-2484(91)90053-X

Kappelman, J., 1988. Morphology and locomotor adaptations of the bovid femur in relation to habitat. Journal of Morphology 198, 119-130. https://doi.org/10.1002/jmor.1051980111

Kappelman, J., Plummer, T., Bishop, L., Duncan, A., Appleton, S., 1997. Bovids as indicators of Plio-Pleistocene paleoenvironments in East Africa. Journal of Human Evolution 32, 229-256. https://doi.org/10.1006/jhev.1996.0105

Klingenberg, C.P., 2016. Size, shape, and form: concepts of allometry in geometric morphometrics. Dev Genes Evol 226, 113-137. https://doi.org/10.1007/s00427-0160539-2

Klingenberg, C.P., 2013. Visualizations in geometric morphometrics: how to read and how to make graphs showing shape changes. Hystrix It. J. Mamm. 24, 15-24. https://doi.org/10.4404/hystrix-24.1-7691

Lewton, K.L., Brankovic, R., Byrd, W.A., Cruz, D., Morales, J., Shin, S., 2020. The effects of phylogeny, body size, and locomotor behavior on the three-dimensional shape of the pelvis in extant carnivorans. PeerJ 8, e8574. https://doi.org/10.7717/peerj.8574

Mallet, C., Cornette, R., Billet, G., Houssaye, A., 2019. Interspecific variation in the limb long bones among modern rhinoceroses-extent and drivers. PeerJ 7, e7647. https://doi.org/10.7717/peerj.7647

Martin, M.L., Travouillon, K.J., Sherratt, E., Fleming, P.A., Warburton, N.M., 2019. Covariation between forelimb muscle anatomy and bone shape in an Australian scratch-digging marsupial: Comparison of morphometric methods. Journal of Morphology 280, 1900-1915. https://doi.org/10.1002/jmor.21074 
Mendoza, M., Palmqvist, P., 2006. Characterizing adaptive morphological patterns related to habitat use and body mass in Bovidae (Mammalia: Artiodactyla). Acta Zoologica Sinica 52, 971-987.

Mitteroecker, P., Gunz, P., 2009. Advances in Geometric Morphometrics. Evolutionary Biology 36, 235-247. https://doi.org/10.1007/s11692-009-9055-x

Mungall, D.E.C., 2007. Exotic Animal Field Guide: Nonnative Hoofed Mammals in the United States, Illustrated Edition. ed. Texas A\&M University Press, College Station.

Plummer, T.W., Bishop, L.C., Hertel, F., 2008. Habitat preference of extant African bovids based on astragalus morphology: operationalizing ecomorphology for palaeoenvironmental reconstruction. Journal of Archaeological Science 35, 30163027. https://doi.org/10.1016/j.jas.2008.06.015

Plummer, T.W., Ferraro, J.V., Louys, J., Hertel, F., Alemseged, Z., Bobe, R., Bishop, L., 2015. Bovid ecomorphology and hominin paleoenvironments of the Shungura Formation, lower Omo River Valley, Ethiopia. Journal of human evolution 88, 108126.

Polly, D., 2008. Limbs in Mammalian Evolution, in: Hall, B.K. (Ed.), Fins into Limbs: Evolution, Development, and Transformation. University of Chicago Press, Chicago, pp. 245-268.

Püschel, T.A., Sellers, W.I., 2016. Standing on the shoulders of apes: Analyzing the form and function of the hominoid scapula using geometric morphometrics and finite element analysis. American Journal of Physical Anthropology 159, 325-341. https://doi.org/10.1002/ajpa.22882

R Development Core Team, 2005. R: A language and environment for statistical computing. $R$ Foundation for Statistical Computing, Vienna, Austria.

Rohlf, F.J., Slice, D., 1990. Extensions of the Procrustes Method for the Optimal Superimposition of Landmarks. Syst Biol 39, 40-59. https://doi.org/10.2307/2992207

RStudio, Inc., 2018. RStudio. Boston, MA.

San Millán, M., Kaliontzopoulou, A., Rissech, C., Turbón, D., 2015. A geometric morphometric analysis of acetabular shape of the primate hip joint in relation to locomotor behaviour. Journal of Human Evolution 83, 15-27. https://doi.org/10.1016/j.jhevol.2015.03.007

Schlager, S., Jefferis, G., Dryden, I., 2018. Morpho: a toolbox providing methods for dataacquisition, visualisation and statistical methods related to Geometric Morphometrics and shape analysis.

Schmidt-Nielsen, K., 1984. Scaling: Why is Animal Size So Important? Cambridge University Press, Cambridge.

Scott, K.M., 1985. Allometric trends and locomotor adaptations in the Bovidae. Bulletin of the AMNH 179.

Scott, R.S., Barr, W.A., 2014. Ecomorphology and phylogenetic risk: Implications for habitat reconstruction using fossil bovids. J. Hum. Evol. 73, 47-57. https://doi.org/10.1016/j.jhevol.2014.02.023

Streiner, D.L., Norman, G.R., 2011. Correction for Multiple Testing: Is There a Resolution? Chest 140, 16-18. https://doi.org/10.1378/chest.11-0523

Walmsley, A., Elton, S., Louys, J., Bishop, L.C., Meloro, C., 2012. Humeral epiphyseal shape in the felidae: The influence of phylogeny, allometry, and locomotion. Journal of Morphology 273, 1424-1438. https://doi.org/10.1002/jmor.20084

Wiley, D.F., 2005. Landmark. Institute for Data Analysis and Visualization.

Wilson, D.E., Mittermeier, R.A., 2011. Handbook of the Mammals of the World. Lynx Edicions, Barcelona.

Zelditch, M.L., Swiderski, D.L., Sheets, H.D., 2012. Geometric Morphometrics for Biologists: A Primer. Academic Press. 


\section{Supplementary files}

892 Table S1. List of all the specimens studied. "X"; bone studied. Hum: humerus, Rad: radius-

893 ulna, Fem: femur, Tib: tibia.

\begin{tabular}{|c|c|c|c|c|c|c|}
\hline Tribe & Species & Collection number & Hum & Rad & Fem & Tib \\
\hline Alcelaphini & Alcelaphus buselaphus & MNHN-ZM-1899-238 & $x$ & & & \\
\hline Alcelaphini & Alcelaphus buselaphus & MNHN-ZM-1902-1410 & & & $x$ & $x$ \\
\hline Alcelaphini & Alcelaphus buselaphus & ZMB-71862 & $x$ & & $x$ & $x$ \\
\hline Alcelaphini & Connochaetes gnou & MNHN-ZM-1976-344 & $x$ & $x$ & $x$ & $x$ \\
\hline Alcelaphini & Connochaetes gnou & MNHN-ZM-2013-26 & $x$ & $x$ & $x$ & $x$ \\
\hline Alcelaphini & Damaliscus pygargus & ZMB-70722 & $x$ & $x$ & $x$ & $x$ \\
\hline Alcelaphini & Damaliscus pygargus & ZMB-71265 & $x$ & $x$ & $x$ & $x$ \\
\hline Antilopini & Antidorcas marsupialis & MNHN-ZM-1993-1670 & $x$ & & $x$ & $x$ \\
\hline Antilopini & Antidorcas marsupialis & MNHN-ZM-1971-89 & & & $x$ & $x$ \\
\hline Antilopini & Antilope cervicapra & MNHN-ZM-1901-174 & $x$ & $x$ & $x$ & $x$ \\
\hline Antilopini & Antilope cervicapra & MNHN-ZM-1992-618 & $x$ & & $x$ & $x$ \\
\hline Antilopini & Dorcatragus megalotis & MNHN-ZM-1915-32 & & & $x$ & \\
\hline Antilopini & Eudorcas thomsonii & MNHN-ZM-1961-41 & $\mathrm{x}$ & & & $x$ \\
\hline Antilopini & Eudorcas thomsonii & MNHN-ZM-1962-384 & $x$ & & $x$ & $x$ \\
\hline Antilopini & Gazella dorcas & MNHN-ZM-1968-803 & $x$ & & $x$ & \\
\hline Antilopini & Gazella dorcas & MNHN-ZM-1974-113 & $x$ & $x$ & $x$ & $x$ \\
\hline Antilopini & Litocranius walleri & MNHN-ZM-1946-82 & & $x$ & & $x$ \\
\hline Antilopini & Madoqua kirkii & MNHN-ZM-1917-17 & & & $x$ & \\
\hline Antilopini & Madoqua kirkii & ZMB-77194 & $x$ & & $x$ & \\
\hline Antilopini & Nanger dama & ZMB-68971 & $x$ & & $x$ & $x$ \\
\hline Antilopini & Nanger dama & ZMB-83430 & $x$ & $x$ & $x$ & $x$ \\
\hline Antilopini & Ourebia ourebi & MNHN-ZM-1972-93 & $x$ & $x$ & $x$ & $x$ \\
\hline Antilopini & Ourebia ourebi & ZMB-77195 & $x$ & & $x$ & $x$ \\
\hline Antilopini & Raphicerus campestris & MNHN-ZM-1962-4187 & & $x$ & & \\
\hline Antilopini & Saiga tatarica & MNHN-ZM-1964-313 & $x$ & $x$ & $x$ & $x$ \\
\hline Antilopini & Saiga tatarica & MNHN-ZM-1959-177 & & & $x$ & \\
\hline Boselaphini & Boselaphus tragocamelus & MNHN-ZM-1864-103 & $x$ & $x$ & $x$ & $x$ \\
\hline Boselaphini & Boselaphus tragocamelus & MNHN-ZM-1907-146 & $x$ & $x$ & $x$ & $x$ \\
\hline Boselaphini & Tetracerus quadricornis & MNHN-ZM-1993-4627 & $x$ & & $x$ & $x$ \\
\hline Boselaphini & Tetracerus quadricornis & MNHN-ZM-1988-223 & $x$ & $x$ & $x$ & $x$ \\
\hline Bovini & Bison bison & MNHN-ZM-1885-339 & $x$ & $x$ & $x$ & $x$ \\
\hline Bovini & Bison bison & MNHN-ZM-1902-316 & $x$ & $x$ & $x$ & $x$ \\
\hline Bovini & Bos frontalis & MNHN-ZM-1970-280 & $x$ & $x$ & $x$ & $x$ \\
\hline Bovini & Bos frontalis & MNHN-ZM-1965-120 & $x$ & & $x$ & $x$ \\
\hline Bovini & Bos grunniens & MNHN-ZM-2008-107 & $x$ & $x$ & & $x$ \\
\hline Bovini & Bos grunniens & MNHN-ZM-1886-300 & $x$ & $x$ & $x$ & $x$ \\
\hline Bovini & Bos javanicus & MNHN-ZM-1944-101 & $x$ & $x$ & $x$ & $x$ \\
\hline Bovini & Bos javanicus & MNHN-ZM-1967-1689 & $x$ & & $x$ & $x$ \\
\hline
\end{tabular}




\begin{tabular}{|c|c|c|c|c|c|c|}
\hline Bovini & Bos taurus & MNHN-ZM-A-10916 & $x$ & $x$ & $x$ & \\
\hline Bovini & Bos taurus & MNHN-ZM-1926-302 & $x$ & $x$ & $x$ & $\mathrm{x}$ \\
\hline Bovini & Bubalus bubalis & MNHN-ZM-1857-19 & $x$ & $x$ & $x$ & $x$ \\
\hline Bovini & Bubalus bubalis & MNHN-ZM-1863-65 & $x$ & $x$ & $x$ & $x$ \\
\hline Bovini & Bubalus depressicornis & MNHN-ZM-2009-421 & $x$ & $x$ & $x$ & $\mathrm{x}$ \\
\hline Bovini & Bubalus depressicornis & MNHN-ZM-SSN & $x$ & $x$ & $x$ & $\mathrm{x}$ \\
\hline Bovini & Syncerus caffer & MNHN-ZM-1936-72 & $x$ & $x$ & $x$ & $x$ \\
\hline Caprini & Ammotragus lervia & MNHN-ZM-2010-643 & $x$ & $x$ & $x$ & $\mathrm{x}$ \\
\hline Caprini & Ammotragus lervia & MNHN-ZM-1896-439 & $x$ & $x$ & $x$ & $x$ \\
\hline Caprini & Budorcas taxicolor & MNHN-ZM-2017-1199 & & & $x$ & \\
\hline Caprini & Capra hircus & MNHN-ZM-2007-1349 & $x$ & $x$ & $x$ & $\mathrm{x}$ \\
\hline Caprini & Capra hircus & MNHN-ZM-SSN & $x$ & $x$ & $x$ & $\mathrm{x}$ \\
\hline Caprini & Capricornis milneedwardsii & MNHN-ZM-1874-283 & $x$ & $x$ & $x$ & $\mathrm{x}$ \\
\hline Caprini & Hemitragus jemlahicus & MNHN-ZM-1971-68 & $x$ & $x$ & $x$ & \\
\hline Caprini & Hemitragus jemlahicus & MNHN-ZM-1972-133 & $x$ & $x$ & $x$ & $\mathrm{x}$ \\
\hline Caprini & Nemorhaedus goral & MNHN-ZM-1962-153 & & $x$ & $x$ & $\mathrm{x}$ \\
\hline Caprini & Nemorhaedus goral & MNHN-ZM-1963-320 & $x$ & $x$ & $x$ & $\mathrm{x}$ \\
\hline Caprini & Oreamnos americanus & MNHN-ZM-2009-253 & $x$ & $x$ & $x$ & \\
\hline Caprini & Oreamnos americanus & ZMB-67805 & $x$ & $x$ & $x$ & $\mathrm{x}$ \\
\hline Caprini & Ovibos moschatus & MNHN-ZM-1977-43 & $x$ & & $x$ & $\mathrm{x}$ \\
\hline Caprini & Ovibos moschatus & MNHN-ZM-1977-39 & $x$ & & $x$ & \\
\hline Caprini & Ovis aries & MNHN-ZM-2000-438 & $x$ & $x$ & $x$ & $\mathrm{x}$ \\
\hline Caprini & Ovis aries & MNHN-ZM-SSN & $x$ & $x$ & $x$ & $\mathrm{x}$ \\
\hline Caprini & Pseudois nayaur & MNHN-ZM-1972-92 & $x$ & $x$ & $x$ & $x$ \\
\hline Caprini & Pseudois nayaur & MNHN-ZM-1966-136 & $x$ & $x$ & $x$ & \\
\hline Caprini & Rupicapra rupicapra & MNHN-ZM-1923-2326 & $x$ & & $x$ & $x$ \\
\hline Caprini & Rupicapra rupicapra & MNHN-ZM-1995-183 & $x$ & & $x$ & $\mathrm{x}$ \\
\hline Cephalophini & Cephalophus leucogaster & MNHN-ZM-2016-2832 & & & $x$ & $\mathrm{x}$ \\
\hline Cephalophini & Cephalophus silvicultor & MNHN-ZM-1981-1023 & $x$ & $x$ & $x$ & $\mathrm{x}$ \\
\hline Cephalophini & Sylvicapra grimmia & MNHN-ZM-1947-871 & & & $x$ & \\
\hline Hippotragini & Addax nasomaculatus & MNHN-ZM-1970-277 & $x$ & $x$ & $x$ & $\mathrm{x}$ \\
\hline Hippotragini & Hippotragus equinus & MNHN-ZM-1995-147 & $x$ & $x$ & $x$ & $\mathrm{x}$ \\
\hline Hippotragini & Hippotragus equinus & MNHN-ZM-1969-167 & $x$ & $x$ & $x$ & $\mathrm{x}$ \\
\hline Hippotragini & Hippotragus niger & ZMB-SSN & & $x$ & $x$ & $\mathrm{X}$ \\
\hline Hippotragini & Oryx dammah & MNHN-ZM-1905-227 & $x$ & $x$ & $x$ & $x$ \\
\hline Hippotragini & Oryx dammah & MNHN-ZM-1972-106 & $x$ & $x$ & $x$ & $x$ \\
\hline Hippotragini & Oryx gazella & MNHN-ZM-1994-009 & $x$ & $x$ & $x$ & $x$ \\
\hline Hippotragini & Oryx gazella & MNHN-ZM-1997-009 & $x$ & & $x$ & $x$ \\
\hline Hippotragini & Oryx leucoryx & MNHN-ZM-1996-2101 & $x$ & $x$ & $x$ & $x$ \\
\hline Hippotragini & Oryx leucoryx & MNHN-ZM-1996-2100 & $x$ & $x$ & $x$ & $x$ \\
\hline Oreotragini & Oreotragus oreatragus & MNHN-ZM-2007-1388 & $x$ & & $x$ & $x$ \\
\hline Oreotragini & Oreotragus oreatragus & MNHN-ZM-SSN & $x$ & & $x$ & $\mathrm{X}$ \\
\hline Reduncini & Kobus ellipsiprymnus & MNHN-ZM-1974-112 & $x$ & $x$ & $x$ & \\
\hline Reduncini & Kobus ellipsiprymnus & MNHN-ZM-1935-637 & $x$ & $x$ & $x$ & $x$ \\
\hline Reduncini & Redunca redunca & MNHN-ZM-1881-1147 & $x$ & $x$ & $x$ & $\mathrm{X}$ \\
\hline
\end{tabular}




\begin{tabular}{|l|l|l|c|c|c|c|}
\hline Reduncini & Redunca redunca & MNHN-ZM-1923-2173 & $\mathrm{X}$ & & $\mathrm{X}$ & \\
\hline Tragelaphini & Taurotragus oryx & MNHN-ZM-2013-1095 & & & $\mathrm{X}$ & $\mathrm{X}$ \\
\hline Tragelaphini & Taurotragus oryx & MNHN-ZM-AGA-7983 & $\mathrm{X}$ & & & \\
\hline Tragelaphini & Tragelaphus spekii & MNHN-ZM-1980-7 & $\mathrm{X}$ & $\mathrm{X}$ & $\mathrm{X}$ & $\mathrm{X}$ \\
\hline Tragelaphini & Tragelaphus spekii & MNHN-ZM-1983-126 & & $\mathrm{X}$ & $\mathrm{X}$ & $\mathrm{X}$ \\
\hline Tragelaphini & Tragelaphus strepsiceros & ZMB-SSN & $\mathrm{X}$ & $\mathrm{X}$ & $\mathrm{X}$ & $\mathrm{X}$ \\
\hline
\end{tabular}

895 Table S2. Description of the landmarks and curves placed on the humerus.

\begin{tabular}{|c|c|c|}
\hline Type & $\mathbf{N}^{\circ}$ & Description \\
\hline \multirow{23}{*}{ Landmark } & 1 & Most distal point of the border of the humeral head. \\
\hline & 2 & Most lateral point of the border of the humeral head. \\
\hline & 3 & Most medial point of the border of the humeral head. \\
\hline & 4 & $\begin{array}{l}\text { Most anterior point of the border of the humeral head. If the anterior part of } \\
\text { the head is divided by a groove, most anterior point of the lateral part. }\end{array}$ \\
\hline & 5 & Maximum of concavity of the intertubercular groove. \\
\hline & 6 & Anterior extremity of the summit of the greater tuberosity. \\
\hline & 7 & Most proximal point of the greater tuberosity. \\
\hline & 8 & Point of maximum of convexity of the greater tuberosity convexity. \\
\hline & 9 & Most distal point of the greater tuberosity convexity. \\
\hline & 10 & Most proximal point of the lesser tuberosity. \\
\hline & 11 & Postero-distal extremity of the groove of the trochlea \\
\hline & 12 & $\begin{array}{l}\text { Most distal contact point between the groove and the medial ridge of the } \\
\text { trochlea. }\end{array}$ \\
\hline & 13 & Most distal contact point between the trochlea and the capitulum. \\
\hline & 14 & Distal extremity of the groove of the capitulum. \\
\hline & 15 & Distal extremity of the lateral border of the capitulum. \\
\hline & 16 & Proximal extremity of the lateral border of the capitulum. \\
\hline & 17 & Proximal extremity of the groove of the capitulum. \\
\hline & 18 & Most proximal contact point between the trochlea and the capitulum. \\
\hline & 19 & Proximal extremity of the groove of the trochlea. \\
\hline & 20 & $\begin{array}{l}\text { Most proximal contact point between the groove and the medial ridge of the } \\
\text { trochlea. }\end{array}$ \\
\hline & 21 & Summit of the medial epicondyle. \\
\hline & 22 & Summit of the lateral epicondyle. \\
\hline & 23 & Deepest point of the fossa of the musculus extensor digitorum lateralis \\
\hline \multirow{8}{*}{ Curve } & 1 & $\begin{array}{l}\text { From point } 2 \text { to point } 2 \text {. Border of the humeral head, beginning in the anterior } \\
\text { direction. }\end{array}$ \\
\hline & 2 & 9 to 6 . Crest of the greater tuberosity. \\
\hline & 3 & 11 to 20. Medial ridge of the trochlea. \\
\hline & 4 & 11 to 18 . Lateral ridge of the trochlea. \\
\hline & 5 & 11 to 19. Groove of the trochlea. \\
\hline & 6 & 12 to 18. Medial and proximal border of the trochlea. \\
\hline & 7 & 18 to 13. Proximal, lateral and distal border of the capitulum. \\
\hline & 8 & 14 to 17. Groove of the capitulum. \\
\hline
\end{tabular}



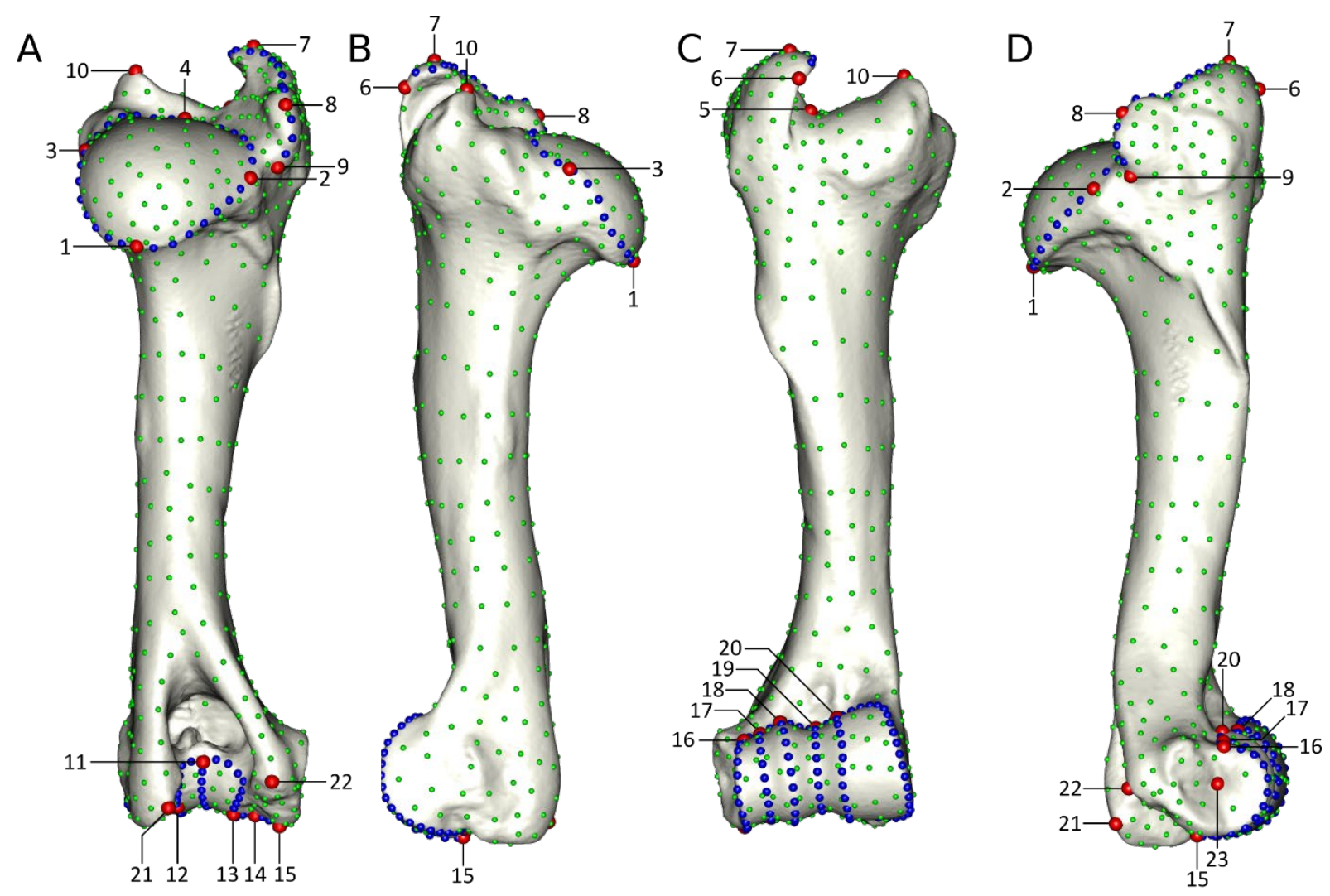

896
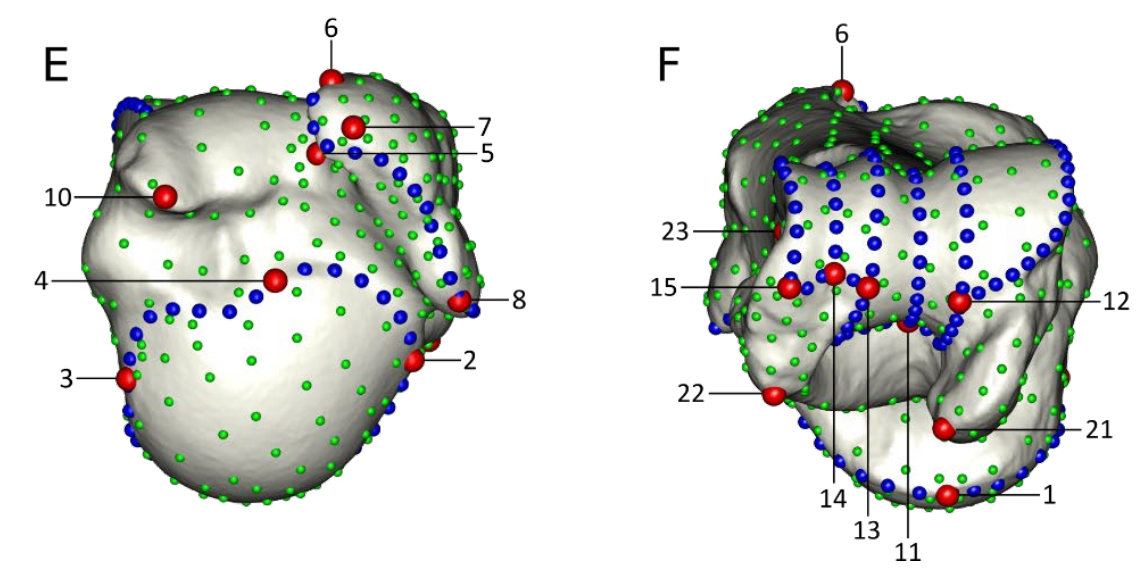

897 Figure S1. Depiction of the anatomical landmarks (red), curve semi-landmarks (blue) and 898 surface semi-landmarks (green) placed on the humerus. Posterior (A), medial (B), anterior (C), 899 lateral (D), proximal (E) and distal (F) views.

900 Table S3. Description of the landmarks and curves placed on the radius-ulna.

\begin{tabular}{|c|c|l|}
\hline Type & $\mathbf{N}^{\mathbf{0}}$ & \multicolumn{1}{c|}{ Description } \\
\hline \multirow{3}{*}{ Landmark } & 1 & Most postero-proximal point of the olecranal tuber. \\
\cline { 2 - 4 } & 2 & Most antero-proximal point of the olecranal tuber. \\
\cline { 2 - 3 } & 3 & Most postero-distal point of the olecranal tuber. \\
\cline { 2 - 4 } & 4 & Anterior extremity of the anconeal process. \\
\hline
\end{tabular}




\begin{tabular}{|c|l|l|}
\hline 5 & $\begin{array}{l}\text { Most proximal contact point between the ulna and the radius, on the lateral } \\
\text { side. }\end{array}$ \\
\hline 7 & $\begin{array}{l}\text { Most proximal contact point between the ulna and the radius, on the medial } \\
\text { side. }\end{array}$ \\
\hline 8 & Most anterior contact point between the articular facet for the capitulum and \\
the trochlea.
\end{tabular}



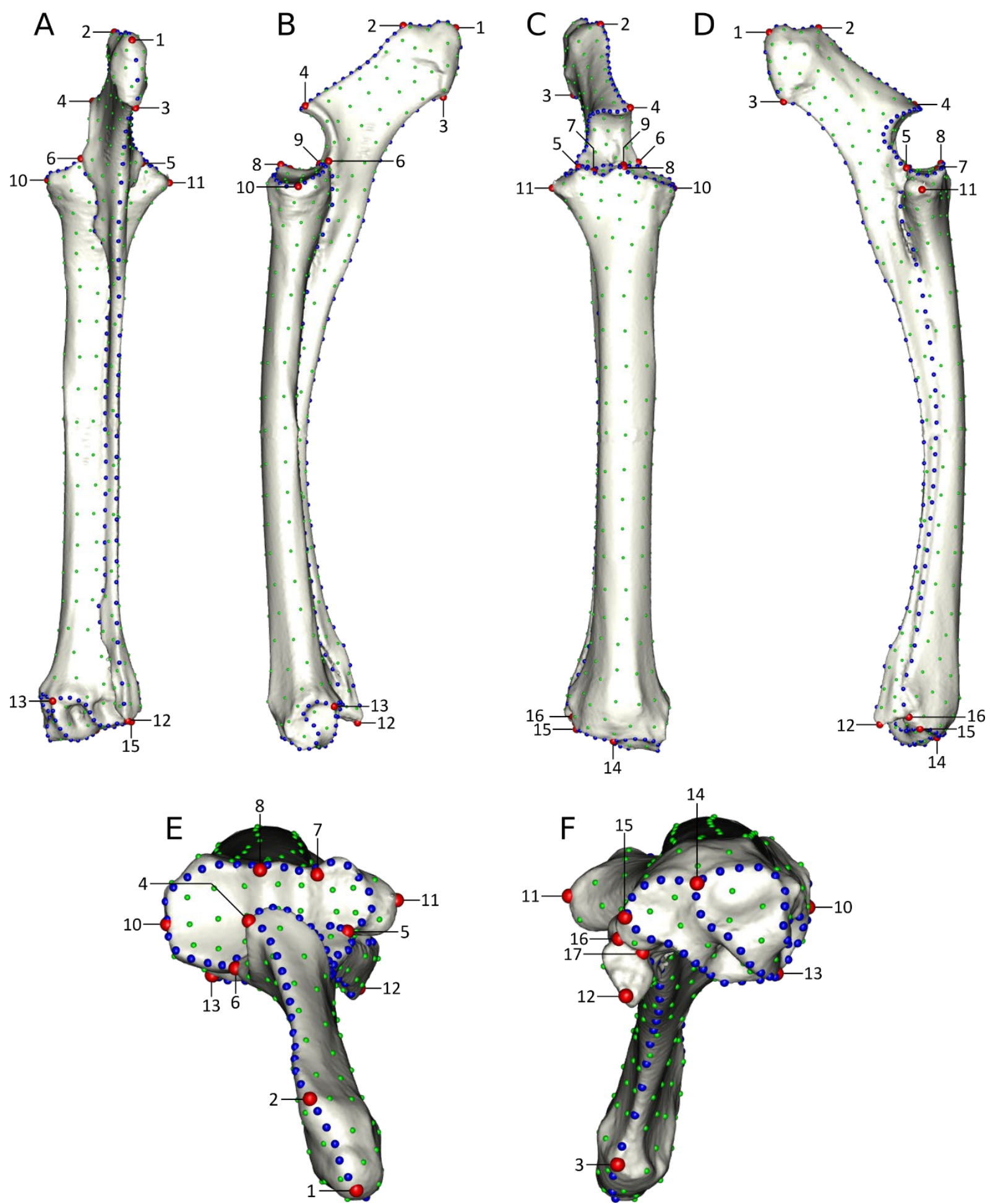

903 Figure S2. Depiction of the anatomical landmarks (red), curve semi-landmarks (blue) and 904 surface semi-landmarks (green) placed on the radius-ulna. Posterior (A), medial (B), anterior 905 (C), lateral (D), proximal (E) and distal (F) views.

906 Table S4. Description of the landmarks and curves placed on the femur. 


\begin{tabular}{|c|c|c|}
\hline \multirow{21}{*}{ Landmark } & 1 & $\begin{array}{l}\text { Most proximal contact point between the head of the femur and the border of } \\
\text { the trochanteric fossa. }\end{array}$ \\
\hline & 2 & Most proximal point of the head of the femur. \\
\hline & 3 & $\begin{array}{l}\text { Contact point between the head of the femur and the crest connecting the lesser } \\
\text { trochanter and the head of the femur. }\end{array}$ \\
\hline & 4 & Most posterior point of the lesser trochanter. \\
\hline & 5 & Most proximal point of the greater trochanter. \\
\hline & 6 & Most distal point of the crest of the greater trochanter. \\
\hline & 7 & $\begin{array}{l}\text { Most anterior contact point between the border of the femoral head and the } \\
\text { neck of the femur. }\end{array}$ \\
\hline & 8 & Most distal point of the border of the trochanteric fossa. \\
\hline & 9 & Proximal extremity of the medial ridge of the trochlea. \\
\hline & 10 & Proximal extremity of the lateral ridge of the trochlea. \\
\hline & 11 & Proximal extremity of the grove of the trochlea. \\
\hline & 12 & Posterior extremity of the medial ridge of the trochlea. \\
\hline & 13 & Posterior extremity of the lateral ridge of the trochlea. \\
\hline & 14 & Posterior extremity of the grove of the trochlea. \\
\hline & 15 & Most proximal point of the border of the medial condyle. \\
\hline & 16 & Most proximal point of the border of the lateral condyle. \\
\hline & 17 & Most posterior point of the centre of the intercondylar fossa. \\
\hline & 18 & Most antero-lateral point of the border of the medial condyle. \\
\hline & 19 & Most antero-medial point of the border of the lateral condyle. \\
\hline & 20 & Most posterior point of the medial condyle. \\
\hline & 21 & Most posterior point of the lateral condyle. \\
\hline \multirow{9}{*}{ Curve } & 1 & $\begin{array}{l}\text { From point } 1 \text { to point } 1 \text {. Border of the femoral head, starting in the posterior } \\
\text { direction. }\end{array}$ \\
\hline & 2 & 1 to 8 . Lateral border of the trochanteric fossa. \\
\hline & 3 & 3 to 4 . Crest connecting the head of the femur to the lesser trochanter. \\
\hline & 4 & 4 to 6. Intertrochanteric crest, and crest of the greater trochanter. \\
\hline & 5 & 9 to 12 . Medial ridge of the trochlea. \\
\hline & 6 & 10 to 13 . Lateral ridge of the trochlea. \\
\hline & 7 & 11 to 14. Grove of the trochlea. \\
\hline & 8 & 18 to 18 . Border of the medial condyle, starting in the medial direction. \\
\hline & 9 & 19 to 19 . Border of the lateral condyle, starting in the medial direction. \\
\hline
\end{tabular}



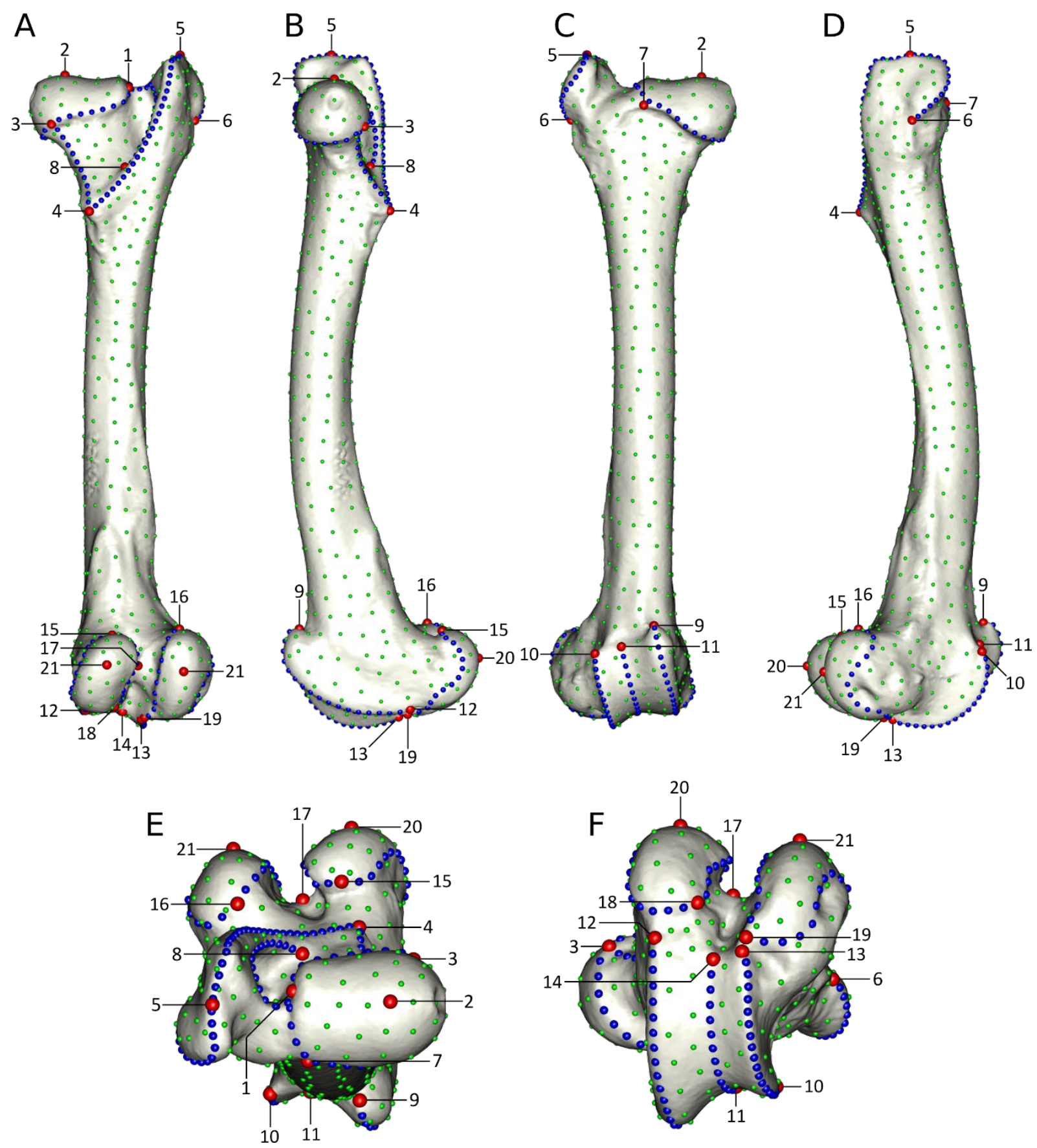

909 Figure S3. Depiction of the anatomical landmarks (red), curve semi-landmarks (blue) and 910 surface semi-landmarks (green) placed on the femur. Posterior (A), medial (B), anterior (C), 911 lateral (D), proximal (E) and distal (F) views.

913 Table S5. Description of the landmarks and curves placed on the tibia.

\begin{tabular}{|c|c|l|}
\hline Type & $\mathbf{N}^{\circ}$ & \multicolumn{1}{c|}{ Description } \\
\hline \multirow{2}{*}{ Landmark } & 1 & Most proximal point of the medial condyle. \\
\cline { 2 - 3 } & 2 & Most anterior point of the medial condyle. \\
\hline
\end{tabular}




\begin{tabular}{|c|c|c|}
\hline & 3 & $\begin{array}{l}\text { Posterior contact point between the medial condyle and the contour of the } \\
\text { proximal epiphysis. }\end{array}$ \\
\hline & 4 & Most proximal point of the lateral condyle. \\
\hline & 5 & Most anterior point of the lateral condyle. \\
\hline & 6 & Most distal point of the lateral condyle. \\
\hline & 7 & $\begin{array}{l}\text { Posterior contact point between the lateral condyle and the contour of the } \\
\text { proximal epiphysis. }\end{array}$ \\
\hline & 8 & Maximum of concavity of the proximal contour of the extensor groove. \\
\hline & 9 & Most lateral point of the border of the tibial tuberosity. \\
\hline & 10 & Most anterior contact point between the tibial tuberosity and the tibial crest. \\
\hline & 11 & Most distal point of the tibial crest. \\
\hline & 12 & Most lateral point of the distal epiphysis. \\
\hline & 13 & Most distal point of the medial malleolus. \\
\hline & 14 & Anterior extremity of the medial groove of the trochlea. \\
\hline & 15 & Anterior extremity of the central ridge of the trochlea. \\
\hline & 16 & Anterior extremity of the lateral groove of the trochlea. \\
\hline & 17 & Posterior extremity of the medial groove of the trochlea. \\
\hline & 18 & Posterior extremity of the central ridge of the trochlea. \\
\hline & 19 & Posterior extremity of the lateral groove of the trochlea. \\
\hline \multirow{10}{*}{ Curve } & 1 & $\begin{array}{l}\text { From point } 2 \text { to point } 2 \text {. Border of the medial condyle, starting in the medial } \\
\text { direction. }\end{array}$ \\
\hline & 2 & 5 to 5 . Border of the lateral condyle, starting in the medial direction. \\
\hline & 3 & 3 to 7 . Posterior part of the border on the proximal epiphysis. \\
\hline & 4 & 11 to 10. Tibial crest. \\
\hline & 5 & $\begin{array}{l}10 \text { to } 5 \text {. Lateral border of the tibial tuberosity, and proximal border of the extensor } \\
\text { groove. }\end{array}$ \\
\hline & 6 & $\begin{array}{l}10 \text { to } 2 \text {. Medial border of the tibial tuberosity and contour of the proximal } \\
\text { epiphysis, up to the medial condyle. }\end{array}$ \\
\hline & 7 & 15 to 15. Border of the trochlea for the astragalus, starting in the lateral direction. \\
\hline & 8 & 14 to 17 . Lateral groove of the trochlea. \\
\hline & 9 & 15 to 18 . Central ridge of the trochlea. \\
\hline & 10 & 16 to 19. Medial groove of the trochlea. \\
\hline
\end{tabular}



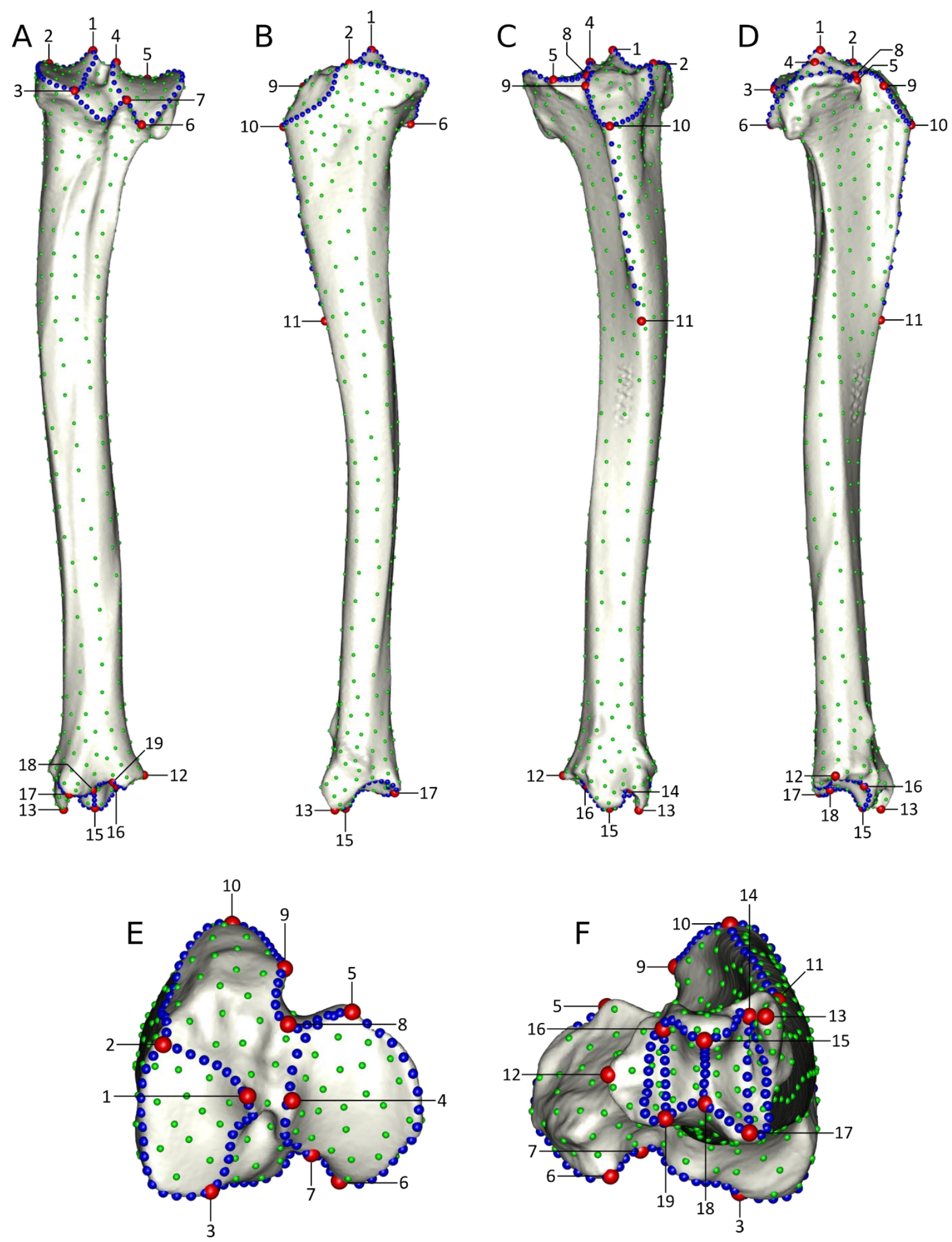

916 Figure S4. Depiction of the anatomical landmarks (red), curve semi-landmarks (blue) and 917 surface semi-landmarks (green) placed on the tibia. Posterior (A), medial (B), anterior (C), 918 lateral (D), proximal (E) and distal (F) views. 
Figure S5. Results of the repeatability tests.
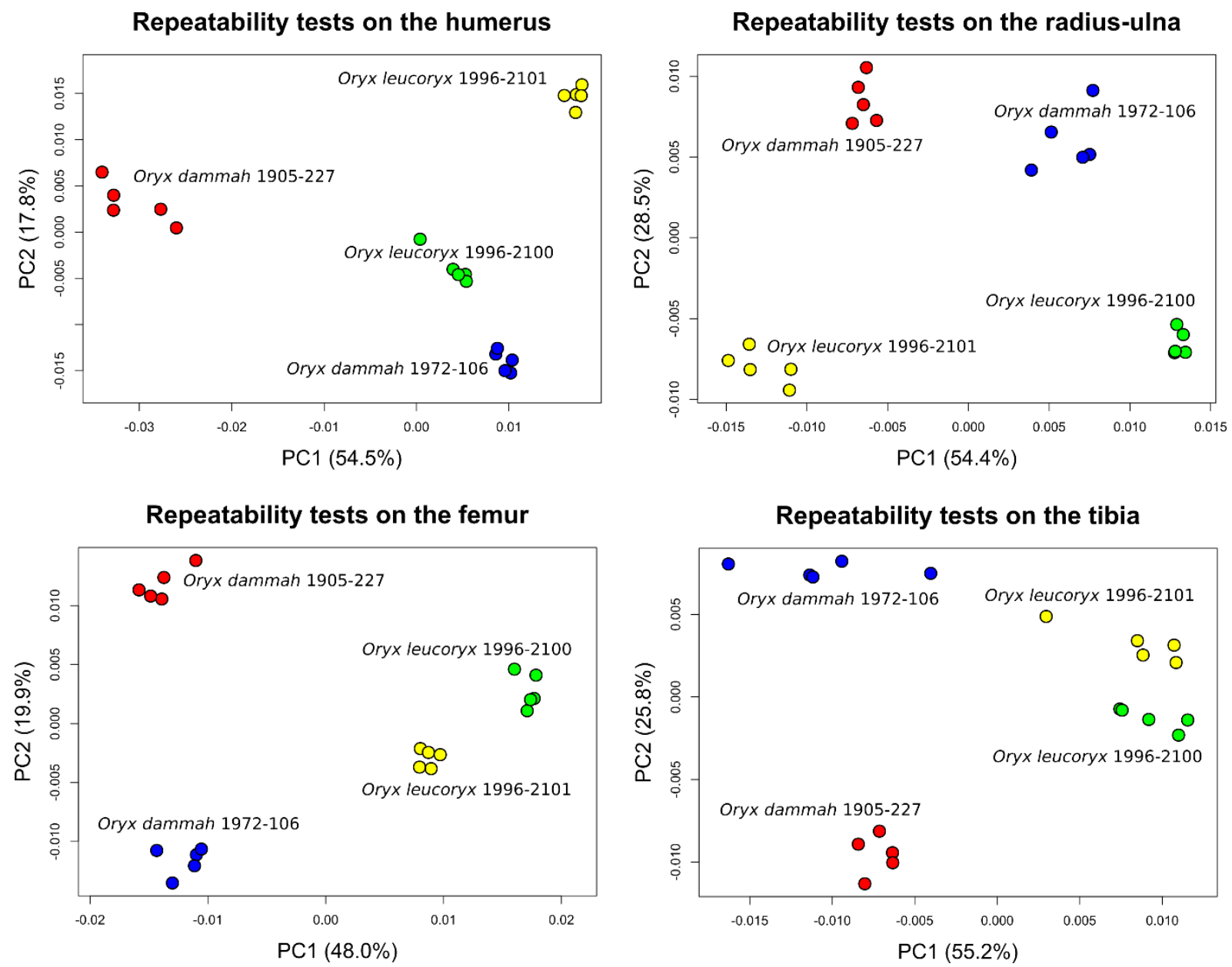

922 Table S6. Result of Student's t-tests showing which habitat categories have different mean masses. Two 923 values are reported: one without a Benjamini-Hochberg correction for multiple pair-wise tests (A), one 924 with the correction (B). The species sampled vary slightly for each bone (cf. Table S1), therefore the 925 test has been done for each bone. The natural logarithm of the mass has been used. P-values below 0.05 926 are shown in bold, p-values between 0.05 and 0.10 in italics.

\begin{tabular}{|c|c|c|c|c|c|c|c|c|c|c|c|}
\hline \multicolumn{12}{|c|}{ A - Without Benjamini---Hochberg correction } \\
\hline \multicolumn{6}{|c|}{ Humerus } & \multicolumn{6}{|c|}{ Radius-Ulna } \\
\hline & $\mathbf{L}$ & $\mathbf{H}$ & $\mathbf{F}$ & $\mathbf{M}$ & D & & $\mathbf{L}$ & $\mathbf{H}$ & $\mathbf{F}$ & $\mathbf{M}$ & D \\
\hline $\mathbf{O}$ & 0.827 & 0.921 & 0.776 & 0.172 & 0.109 & $\mathbf{O}$ & 0.918 & 0.291 & 0.715 & 0.646 & 0.093 \\
\hline $\mathbf{L}$ & $\mathrm{X}$ & 0.924 & 0.943 & 0.377 & 0.325 & $\mathbf{L}$ & $\mathrm{X}$ & 0.339 & 0.685 & 0.864 & 0.129 \\
\hline $\mathbf{H}$ & $\mathrm{X}$ & $\mathrm{X}$ & 0.868 & 0.424 & 0.268 & $\mathbf{H}$ & $\mathrm{X}$ & $\mathrm{X}$ & 0.704 & 0.174 & 0.530 \\
\hline F & $\mathrm{X}$ & $\mathrm{X}$ & $\mathrm{X}$ & 0.427 & 0.408 & $\mathbf{F}$ & $\mathrm{X}$ & $\mathrm{X}$ & $\mathrm{X}$ & 0.593 & 0.408 \\
\hline M & $\mathrm{X}$ & $\mathrm{X}$ & $X$ & $\mathrm{X}$ & 0.029 & M & $X$ & $\mathrm{X}$ & $\mathrm{X}$ & $\mathrm{X}$ & 0.059 \\
\hline \multicolumn{6}{|c|}{ Femur } & \multicolumn{6}{|c|}{ Tibia } \\
\hline & $\mathbf{L}$ & $\mathbf{H}$ & $\mathbf{F}$ & M & D & & $\mathbf{L}$ & H & $\mathbf{F}$ & M & D \\
\hline O & 0.963 & 0.921 & 0.653 & 0.207 & 0.109 & $\mathbf{O}$ & 0.810 & 0.338 & 0.653 & 0.172 & 0.109 \\
\hline $\mathbf{L}$ & $\mathrm{X}$ & 0.960 & 0.665 & 0.393 & 0.201 & $\mathbf{L}$ & $\mathrm{X}$ & 0.549 & 0.577 & 0.266 & 0.231 \\
\hline $\mathbf{H}$ & $\mathrm{X}$ & $\mathrm{X}$ & 0.653 & 0.427 & 0.268 & $\mathbf{H}$ & $\mathrm{X}$ & $\mathrm{X}$ & 0.332 & 0.086 & 0.530 \\
\hline $\mathbf{F}$ & $\mathrm{X}$ & $X$ & $\mathrm{X}$ & 0.873 & 0.181 & $\mathbf{F}$ & $\mathrm{X}$ & $\mathrm{X}$ & $X$ & 0.880 & 0.181 \\
\hline
\end{tabular}




\begin{tabular}{|c|c|c|c|c|c|c|c|c|c|c|c|}
\hline $\mathbf{M}$ & $\mathrm{X}$ & $\mathrm{X}$ & $X$ & $\mathrm{X}$ & 0.029 & M & $\mathrm{X}$ & $X$ & $\mathrm{X}$ & $\mathrm{X}$ & 0.029 \\
\hline \multicolumn{12}{|c|}{ B - With Benjamini-Hochberg correction } \\
\hline \multicolumn{6}{|c|}{ Humerus } & \multicolumn{6}{|c|}{ Radius-Ulna } \\
\hline & $\mathbf{L}$ & $\mathbf{H}$ & $\mathbf{F}$ & $\mathbf{M}$ & D & & $\mathbf{L}$ & $\mathbf{H}$ & $\mathbf{F}$ & $\mathbf{M}$ & D \\
\hline $\mathbf{O}$ & 0.943 & 0.943 & 0.943 & 0.712 & 0.712 & $\mathbf{O}$ & 0.918 & 0.825 & 0.825 & 0.825 & 0.644 \\
\hline $\mathbf{L}$ & $\mathrm{X}$ & 0.943 & 0.943 & 0.712 & 0.712 & $\mathbf{L}$ & $X$ & 0.825 & 0.825 & 0.918 & 0.644 \\
\hline $\mathbf{H}$ & $\mathrm{X}$ & $\mathrm{X}$ & 0.943 & 0.712 & 0.712 & $\mathbf{H}$ & $\mathrm{X}$ & $\mathrm{X}$ & 0.825 & 0.652 & 0.825 \\
\hline $\mathbf{F}$ & $\mathrm{X}$ & $\mathrm{X}$ & $\mathrm{X}$ & 0.712 & 0.712 & $\mathbf{F}$ & $\mathrm{X}$ & $\mathrm{X}$ & $\mathrm{X}$ & 0.825 & 0.825 \\
\hline $\mathbf{M}$ & $\mathrm{X}$ & $\mathrm{X}$ & $X$ & $\mathrm{X}$ & 0.436 & M & $\mathrm{X}$ & $\mathrm{X}$ & $\mathrm{X}$ & $X$ & 0.644 \\
\hline \multicolumn{6}{|c|}{ Femur } & \multicolumn{6}{|c|}{ Tibia } \\
\hline & $\mathbf{L}$ & $\mathbf{H}$ & $\mathbf{F}$ & M & D & & $\mathbf{L}$ & $\mathbf{H}$ & $\mathbf{F}$ & M & D \\
\hline $\mathbf{O}$ & 0.963 & 0.963 & 0.906 & 0.620 & 0.620 & $\mathbf{O}$ & 0.867 & 0.563 & 0.753 & 0.543 & 0.543 \\
\hline $\mathbf{L}$ & $X$ & 0.963 & 0.906 & 0.801 & 0.620 & $\mathbf{L}$ & $X$ & 0.721 & 0.721 & 0.563 & 0.563 \\
\hline $\mathbf{H}$ & $\mathrm{X}$ & $\mathrm{X}$ & 0.906 & 0.801 & 0.670 & $\mathbf{H}$ & $X$ & $\mathrm{X}$ & 0.563 & 0.543 & 0.721 \\
\hline $\mathbf{F}$ & $X$ & $\mathrm{X}$ & $X$ & 0.963 & 0.620 & $\mathbf{F}$ & $X$ & $X$ & $X$ & 0.880 & 0.543 \\
\hline $\mathbf{M}$ & $\mathrm{X}$ & $X$ & $X$ & $\mathrm{X}$ & 0.432 & M & $\mathrm{X}$ & $X$ & $\mathrm{X}$ & $\mathrm{X}$ & 0.436 \\
\hline
\end{tabular}

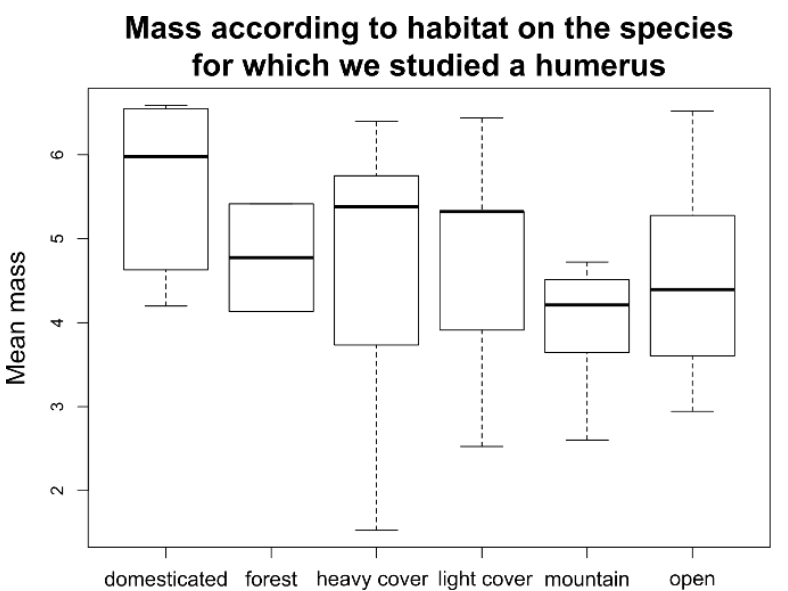

Habitat

Mass according to habitat on the species for which we studied a femur

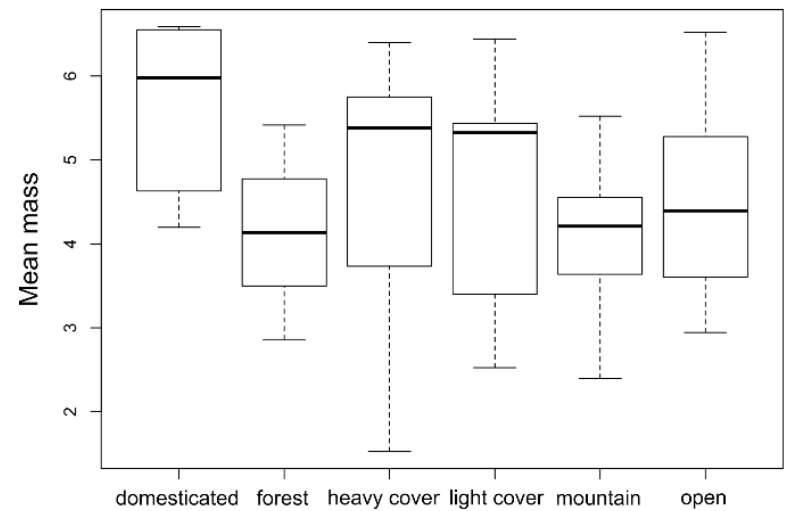

Habitat

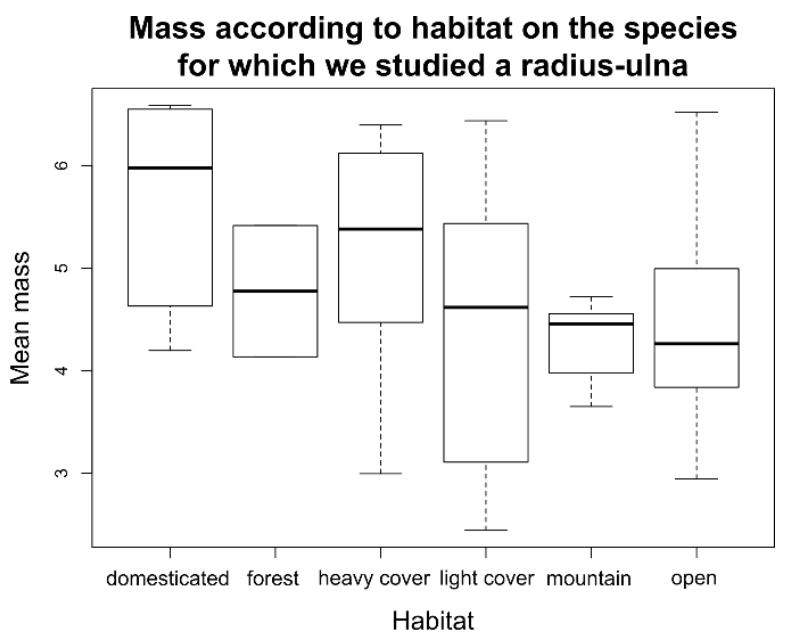

Mass according to habitat on the species for which we studied a tibia

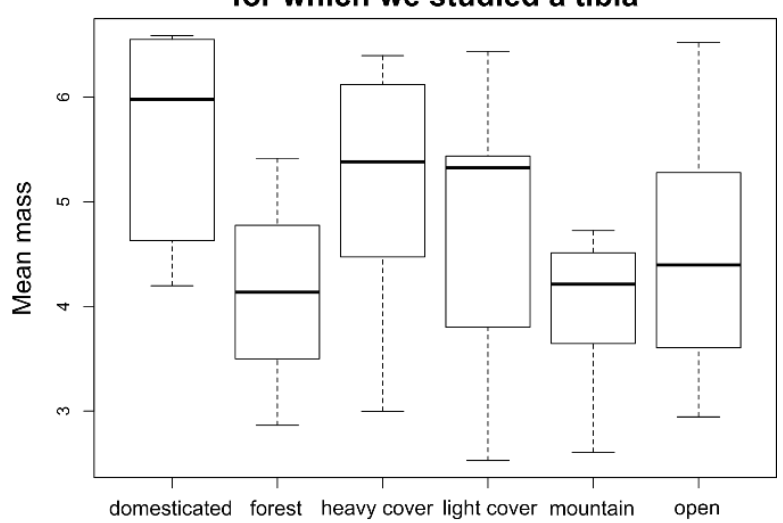

Habitat

929 Figure S6. Boxplot representing the distribution of the logarithm of species' mean mass (in $\mathrm{kg}$ ) in each

930 habitat category. The species sampled vary slightly for each bone (Table S1), therefore the graph is

931 shown for each bone. 